\title{
The state of pore fluid pressure and 3D megathrust earthquake dynamics
}

Elizabeth H. Madden ${ }^{1}$, Thomas Ulrich ${ }^{2}$, Alice-Agnes Gabriel ${ }^{2}$

${ }^{1}$ Observatorio Sismológico, Instituto de Geociências, Universidade de Brasília, Brasília, Brazil, betsymadden@gmail.com

${ }^{2}$ Department of Earth and Environmental Sciences, Ludwig-Maximilians-Universität München, Munich, Germany

ulrich@geophysik.uni-muenchen.de

gabriel@geophysik.uni-muenchen.de

This paper is a non-peer reviewed preprint submitted to EarthArXiv. It was submitted to the journal Earth and Planetary Science Letters on April 8, 2021. 


\title{
The state of pore fluid pressure and 3D megathrust earthquake dynamics
}

\author{
Elizabeth H. Madden ${ }^{1}$, Thomas Ulrich, ${ }^{2 *}$, Alice-Agnes Gabriel, ${ }^{2}$ \\ ${ }^{1}$ Observatório Sismológico, Instituto de Geociências, Universidade de Brasília, Brasília, Brazil \\ ${ }^{2}$ Department of Earth and Environmental Sciences, Ludwig-Maximilians-Universität München, Munich, \\ Germany

\section{Key Points:} \\ - Very high coseismic pore fluid pressure at $97 \%$ of the lithostatic pressure supported \\ by dynamic rupture modeling. \\ - Very high coseismic pore fluid pressure causes peak slip and peak slip rate at shal- \\ lower depths, underscoring the importance of characterizing near-trench conditions \\ to characterize megathrust hazard. \\ - Apparent co-seismic principal stress rotations and heterogeneous absolute post- \\ seismic stress state are consistent with a variety of aftershock focal mechanisms.
}

Corresponding author: Elizabeth H. Madden, betsymadden@gmail.com 
Abstract

\section{Abstract}

The importance of pore fluid pressure $\left(P_{f}\right)$ for fault strength, stress state and slip behavior holds promise for explaining spatio-temporal subduction zone megathrust behavior, but the coseismic state of $P_{f}$ and its distribution with depth are poorly constrained. Here, we analyze fault stress states and 3D rupture dynamics of six scenarios based on the $2004 M_{w}$ 9.1 Sumatra-Andaman earthquake. We vary $P_{f}$ from hydrostatic to lithostatic under two different gradients that result in depth-dependent versus constant effective normal stress on the seismogenic part of the megathrust. As $P_{f}$ magnitude increases, fault strength, moment magnitude, cumulative slip, peak slip rate, dynamic stress drop and rupture velocity decrease. When $P_{f}$ follows the lithostatic gradient, depth-constant effective normal stress results, as theoretically proposed. We find that such a near-lithostatic pore fluid pressure gradient shifts peak slip and peak slip rate up-dip. We study the dynamically modeled apparent co-seismic principal stress rotations and absolute post-seismic stress state. In all earthquake dynamic rupture scenarios, the mean apparent stress rotations are larger in the accretionary wedge than below the megathrust. Scenarios with higher $P_{f}$ exhibit lower mean apparent principal stress rotations in the accretionary wedge. By comparison against observations of the 2004 Sumatra-Andaman earthquake, two preferred scenarios emerge. These support the presence of very high coseismic pore fluid pressure at $97 \%$ of the lithostatic pressure, producing average shear and effective normal traction magnitudes of 4-5 MPa and $22 \mathrm{MPa}$, respectively. The mean dynamic stress drop for both scenario earthquakes is $3 \mathrm{MPa}$ and the mean rupture velocity is $2400-2600 \mathrm{~m} / \mathrm{s}$, comparable to observations of the 2004 Sumatra earthquake. The heterogeneous postseismic stress states in these scenarios are consistent with the variety of aftershock focal mechanisms observed after the 2004 earthquake. These two preferred scenarios differ in pore fluid pressure gradient and thus in slip on the shallow megathrust. Under conditions of very high pore fluid pressure that lead to weak megathrusts in terms of the low static shear strength and low dynamic friction during rupture, near-trench strength and constitutive behavior are crucial for megathrust hazard, as peak slip and peak slip rate occur at shallower depths. This condition also is consistent with observations that the stress drops of small earthquakes in subduction zones are only weakly depth-dependent. 


\section{Plain Language Summary}

[Required for GRL]

\section{Introduction}

Pore fluid pressure $\left(P_{f}\right)$ differences are used to explain spatial and temporal variations in slip behavior observed in subduction zones (e.g., Saffer \& Tobin, 2011). At the base of the seismogenic zone, high $P_{f}$ is linked to low effective stress conditions and slow slip (Bürgmann, 2018). Slow slip behavior observed deep along the Cascadia subduction zone is attributed to hydrofracturing of the barrier trapping fluids in the down-going plate, allowing fluids to circulate (Audet et al., 2009). At Cascadia, high ratios of P-wave to S-wave speed $(\mathrm{Vp} / \mathrm{Vs})$ observed from receiver functions are inconsistent with lithology, but can be explained by near-lithostatic $P_{f}$ (Audet et al., 2009).

In seismogenic regions of subduction zones, lower $P_{f}$ conditions have been proposed as a mechanism for locking there (Saffer \& Tobin, 2011). Heise et al. (2017) co-locate a geodetically-identified locked region with a patch of high electrical resistivity attributed to lack of fluid or low $P_{f}$ on the Hikurangi subduction interface, while shallow creep occurs in a region of conductivity that can be explained by high fluid production or high $P_{f}$ (Heise et al., 2013). However, heat flow studies (Gao \& Wang, 2014) and force-balance inversions (Lamb, 2006) find shear to normal stress ratios that indicate high $P_{f}$ near the megathrust. Lamb (2006) finds evidence for $P_{f}$ at $95 \%$ of the lithostatic pressure at 7 of 9 subduction zones, including Sumatra. Two exceptions to this are Northern Chile and Tonga, with $P_{f}$ at $81 \%$ of the lithostatic pressure.

Temporal variation in $P_{f}$ is central to the fault-valve model of Sibson (1992), which attributes earthquakes to both tectonic loading (shear stress building until an earthquake occurs) and fluid-pressure cycling $\left(P_{f}\right.$ building and effective normal stress falling over time until an earthquake occurs). Petrini et al. (2020) show that fluid pressure variations in time can control subduction zone seismic cycling. In addition, observed increases in Vp/Vs following the 1995 M 8 Antofagasta earthquake (Husen \& Kissling, 2002) suggest the rapid movement of fluid during or directly after megathrust earthquakes. EberhartPhillips et al. (1989) note that such changes can occur only when fluid pressures are nearlithostatic. 
This variety of observations and inferences about $P_{f}$ in subduction zones is reflected in the variety of ways that $P_{f}$ is considered in investigations of megathrust mechanics and earthquake modeling. Hydrostatic, depth-dependent $P_{f}$ gradients may be used when inferring fault static and dynamic strength components. For example, drilling to $820 \mathrm{~m}$ depth after the Tohoku earthquake, Fulton et al. (2013) infer a residual shear stress of $0.54 \mathrm{MPa}$ from temperature variations close to the fault that are attributed to frictional heating during $50 \mathrm{~m}$ of slip under hydrostatic $P_{f}$ conditions. This shear stress estimate has been revised slightly, resulting in a median estimate of $0.52 \mathrm{MPa}$ and a range from 0.30-1.2 MPa (Brodsky et al., 2020), also under hydrostatic conditions. Di Toro et al. (2011) use a hydrostatic $P_{f}$ gradient to extrapolate experimental estimates of the thermal weakening distance to depth.

In faulting and earthquake models, $P_{f}$ is considered in several ways. Quasistatic models of fault slip may not incorporate $P_{f}$ explicitly, but set realistic stress gradients that produce reasonable fault slip distributions (Madden et al., 2013). Models of earthquake sequences and rupture dynamics commonly prescribe normal stress following effective stress theory as $\sigma_{n}-P_{f}$, where $\sigma_{n}$ is the compressive normal stress (Hubbert $\&$ Rubey, 1959). $P_{f}$ typically varies with depth, and is chosen ad-hoc to help reconcile realistic earthquake characteristics with friction and fault shear strength (e.g. Kozdon \& Dunham, 2013; Ulrich et al., 2019). Others initialize dynamic rupture models with conditions, including $P_{f}$ conditions, from geodynamic and seismic cycling modeling that captures long term subduction zone deformation and fluid flow (I. Zelst et al., 2019; Wirp et al., 2021; Madden et al., 2021).

Rice (1992) shows that fluid at elevated pressures within a fault zone may follow the same gradient with depth as the lithostatic stress, causing constant effective normal stress with depth. Data from crustal sedimentary rocks support this theory (Suppe, 2014). This condition is assumed in some dynamic rupture models (e.g., Ramos et al., 2021), but not others (e.g., Kozdon \& Dunham, 2013; Ulrich et al., 2020). Other models consider the coupled, dynamic effects of fluids, such as dilatancy (e.g., Segall \& Rice, 1995) and thermal pressurization (e.g., Garagash, 2012). Recent earthquake sequence modeling by Zhu et al. (2020) couples earthquake and pore fluid dynamics by incorporating fluid migration and periodic $P_{f}$ variations over earthquake cycles. These models produce fluid-driven aseismic slip at the base of the seismic zone, large earthquakes and earthquake swarms. 2D seismo-hydro-mechanical modeling of subduction zone earthquake cy- 
cling show high $P_{f}$ moving progressively updip due to compaction inside an evolving fault, eventually leading to a seismic event (Petrini et al., 2020).

While coseismic $P_{f}$ can be inferred from these observations and inferences, it has not been measured directly and little data is available, particularly deep along subduction zones. Few studies integrate knowledge about megathrust mechanics with megathrust earthquake rupture dynamics to study coseismic $P_{f}$. To supplement this gap, we explore the dynamic effects of different ideas about $P_{f}$ magnitudes and gradients in megathrust systems using a 3D dynamic earthquake rupture and seismic wave propagation model based on the 2004 Sumatra-Andaman earthquake. This model was demonstrated to match near- and far-field seismic, geodetic, geological, and tsunami observations of the 2004 SumatraAndaman earthquake and Indian Ocean tsunami (Uphoff et al., 2017; Ulrich et al., 2020). We focus on how various competing hypotheses on $P_{f}$ magnitude and variation with depth affect the co-seismic conditions near the megathrust, and how these conditions influence earthquake characteristics and the postseismic stress field. We generate a series of 6 scenarios under different $P_{f}$ magnitudes and gradients, which create initial conditions of either depth-dependent or constant normal stress near the megathrust. We compare results against observations of the 2004 earthquake and general observational inferences about subduction zone earthquakes. We note that this range of scenarios represents the variety of conditions that may be present along a single megathrust, due to spatial variations in $P_{f}$ magnitude and/or gradient.

\section{Modeling methods}

\subsection{Computational model}

The earthquake models are run with SeisSol (www.seissol.org), a software package that solves for dynamic fault rupture and seismic wave propagation with high-order accuracy in space and time. SeisSol solves the seismic wave equation in velocity-stress formulation using an Arbitrary high-order DERivate Discontinuous Galerkin (ADERDG) scheme (Dumbser \& Käser, 2006). Computational optimizations target supercomputers with many-core CPUs (Breuer et al., 2014). SeisSol uses local time stepping, which increases runtime efficiency by decreasing dependence of the time-step on the element with the smallest radius (Uphoff et al., 2017). Following the SCEC/USGS Dynamic Rup- 

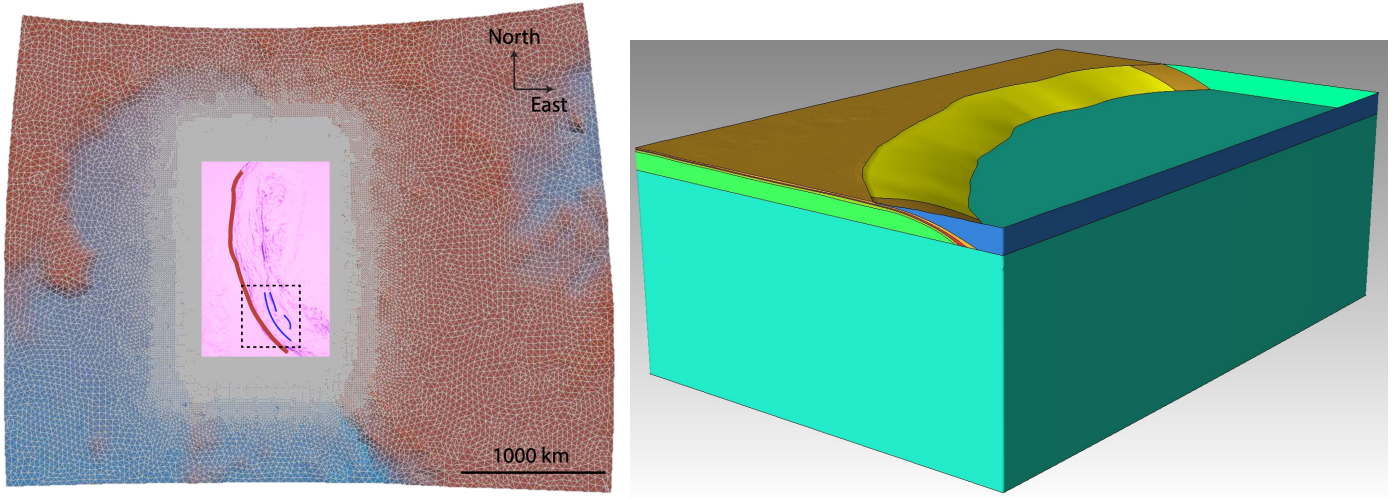

Figure 1. (left) Surface of model mesh showing adaptive meshing with higher resolution topography and finer meshing near the megathrust (red line is megathrust trace, blue lines are splay fault traces) (adapted from Uphoff et al. (2017)). (right) Zoom and oblique view of the pink region of the structural model shown to the left. Yellow surface is the megathrust. Dipping oceanic crustal layers are built into the mesh; continental crustal layers are assigned by depth. The fault intersects the seafloor to the upper left and reaches $50 \mathrm{~km}$ depth to the lower right. A lower-velocity subduction channel surrounds the megathrust slip surface (Table 1).

ture Code Verification exercises (Harris et al., 2018), SeisSol has been validated against several community benchmarks (De La Puente et al., 2009; Pelties et al., 2014).

\subsection{Structural model}

The structural model and computational mesh are shown in Figure 1. Use of an unstructured tetrahedral mesh allows for a realistic representation of the non-planar slab interface, splay faults, curved oceanic crust and high-resolution bathymetry. The megathrust geometry follows Slab1.0 (Hayes et al., 2012). The mesh for these models has elements with edge lengths of $1 \mathrm{~km}$ along the faults, $4 \mathrm{~km}$ at the surface, and $100 \mathrm{~km}$ in the volume far from the fault; mesh resolution varies gradually between these conditions. We ensure that this element size along the fault is sufficient to capture the cohesive zone with a series of models with different size elements following the analysis in Wollherr et al. (2018). The regional rock properties are adapted from Laske et al. (2013) and shown in Table 1. The oceanic crust layers curve, while the continental crust layers are flat. We assume a linear elastic constitutive law. 
Table 1. Material properties

\begin{tabular}{cccc}
\hline max depth $(\mathrm{km})$ & $V_{p}(\mathrm{~m} / \mathrm{s})$ & $V_{s}(\mathrm{~m} / \mathrm{s})$ & $\rho\left(\mathrm{kg} / \mathrm{m}^{3}\right)$ \\
\hline Continental crust & & & \\
\hline 6 & 6000 & 3500 & 2720 \\
12 & 6600 & 3800 & 2860 \\
23 & 7100 & 3900 & 3050 \\
500 & 8000 & 4450 & 3300 \\
\hline Oceanic crust & & & \\
\hline curved & & & \\
curved $_{\text {curved }}$ & 6000 & 3500 & 2720 \\
curved & 6600 & 3800 & 2860 \\
\hline
\end{tabular}

${ }^{a}$ Layer surrounding the fault.

\section{Model set-up and fault mechanics}

We present 6 earthquake scenarios with different pore fluid pressure $\left(P_{f}\right)$ conditions and thus different initial traction conditions on the megathrust (Table 2). In order to isolate the influence of $P_{f}$ in these scenarios, we choose to maintain the same ratio of shear to effective normal traction $\left(\tau_{s} / \tau_{n}^{\prime}\right)$ in all scenarios, though this ratio changes across the megathrust.

\subsection{Regional stress field and fluid pressure}

The regional stress tensor orientations are taken from inversion of focal mechanisms near the hypocenter (Karagianni et al., 2015) (region 7.1.22). We assume a laterally homogeneous stress tensor. The maximum compressive stress, $\sigma_{3}$, has an azimuth of $225^{\circ}$ and plunges $7^{\circ}$, the intermediate principal stress, $\sigma_{2}$, has an azimuth of $315^{\circ}$ and plunges $7^{\circ}$, and the least compressive stress, $\sigma_{1}$, has an azimuth of $90^{\circ}$ and plunges $80^{\circ}$. Following the effective stress principle (Hubbert \& Rubey, 1959), the stresses are assigned as gradients relative to the effective vertical (or lithostatic) stress, $\sigma_{v}^{\prime}=\rho g z+P_{f}$, where $\rho$ is the density of rock, $g$ is gravitational acceleration, $z$ is depth and $P_{f}$ is the pore fluid pressure. Increasing $P_{f}$ decreases the magnitudes of $\sigma_{v}^{\prime}$, the effective principal stresses ( $\sigma_{3}^{\prime}<\sigma_{2}^{\prime}<\sigma_{1}^{\prime}$, compression is negative), the effective mean stress, and the effective deviatoric stress (e.g., Hirth \& Beeler, 2015). We set $\sigma_{2}^{\prime}$ halfway between $\sigma_{3}^{\prime}$ and $\sigma_{1}^{\prime}$. In all scenarios, we taper the differential stress from $24 \mathrm{~km}$ depth to zero at $50 \mathrm{~km}$ depth to approximate the transition from brittle to ductile deformation. 
Table 2. Initial conditions for all scenarios. Mean values are averaged across the entire fault.

\begin{tabular}{ccccc}
\hline Scenario & $P_{f}$ level $\left(\%\right.$ of $\left.\sigma_{v}{ }^{a}\right)$ & $P_{f}$ condition & mean $\tau_{s}^{b}$ & mean $\tau_{n}^{\prime c}$ \\
\hline 1 & low $(31 \%)$ & $0.31 \sigma_{v}$ & 101 & -506 \\
2 & moderate $(62 \%)$ & $0.62 \sigma_{v}$ & 54 & -277 \\
3 & high $(93 \%)$ & $0.93 \sigma_{v}$ & 10 & -52 \\
4 & very high $(97 \%)$ & $0.97 \sigma_{v}$ & 4 & -22 \\
\hline 5 & high $(93 \%)$ & $\sigma_{v}-42 \mathrm{MPa}$ & 11 & -47 \\
6 & very high $(97 \%)$ & $\sigma_{v}-20 \mathrm{MPa}$ & 5 & -22 \\
\hline
\end{tabular}

${ }^{a}$ vertical stress (lithostatic stress)

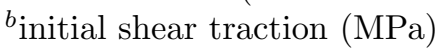

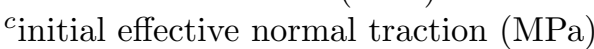

As shown in Table 2, Scenarios 1 to 4 have $P_{f}$ gradients that range from low in Scenario 1 to very high in Scenario 4. $P_{f}$ is hydrostatic $\left(31 \%\right.$ of $\left.\sigma_{v}\right)$ in Scenario 1 and moderate $\left(62 \%\right.$ of $\left.\sigma_{v}\right)$ in Scenario 2 . High and very high $P_{f}$ in scenarios 3 and 4 are set to $93 \%$ and $97 \%$ of $\sigma_{v}$, respectively. As a result of the depth-dependent $P_{f}$ in scenarios 1 to 4 , shear and effective normal stresses are increasing with depth, as shown for Scenario 4 in Figure 2a. In scenarios 5 and 6, we assume that very high $P_{f}$ follows the lithostatic gradient below $5 \mathrm{~km}$ depth, so $P_{f}$ follows the $\sigma_{v}$ gradient, but is shifted by $42 \mathrm{MPa}$ in scenario 5 and by $20 \mathrm{MPa}$ in Scenario 6, representing $93 \%$ and $97 \%$ of $\sigma_{v}$, respectively. As a result, shear and effective normal stresses are constant with depth, as shown for Scenario 6 in Figure 2b. Constant effective normal stress with depth is shown theoretically by Rice (1992). In all scenarios, the shear stress scales with the effective normal stress.

The initial shear and effective normal tractions, $\tau_{s}$ and $\tau_{n}^{\prime}$, are determined by projecting the local effective stress tensor on the non-planar megathrust fault geometry. Our $3 \mathrm{D}$, geometrically complex megathrust modulates the fault traction distribution and may, therefore, depart from the linear loading stress gradients and feature additional spatial variations. These initial conditions are shown for each scenario in Figure 3 and mean values are summarized in Table 2. Across all scenarios, $\tau_{s}$ and $\tau_{n}^{\prime}$ and their averages decrease with increasing $P_{f}$. In Scenarios 1 to 4 , tractions on the megathrust are depth-dependent, but in Scenarios 5 and 6 , they are relatively constant. Note that $\tau_{n}^{\prime}$ varies with fault geometry in all scenarios, including scenarios 5 and 6 , in which there is a variation of up to $\approx 5 \mathrm{MPa}$. Scenarios 5 and 6 extend the theory of Rice (1992), as stresses in the fault zone are not isotropic and this dependence on fault geometry remains. 

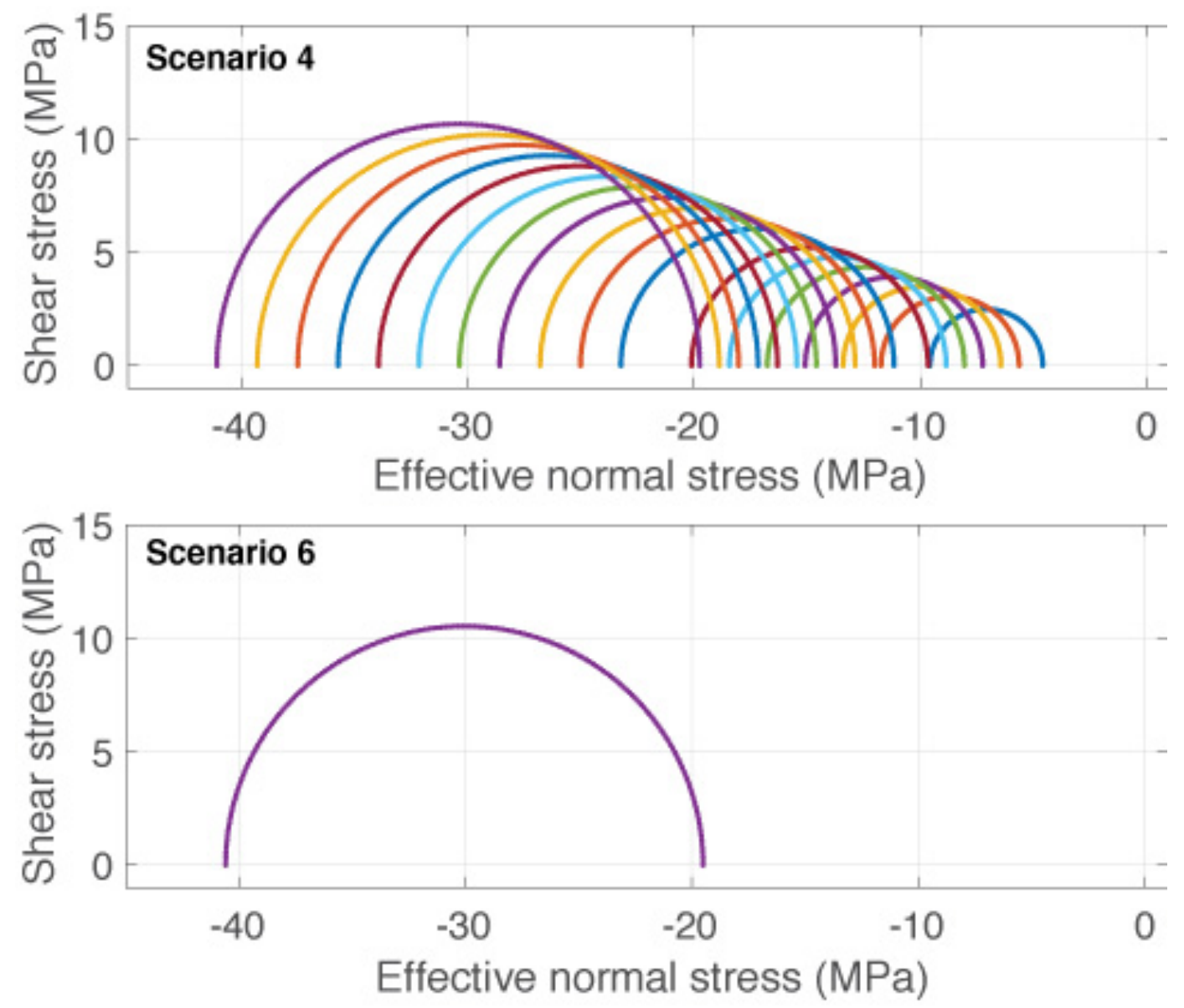

Figure 2. Shear and effective normal stress from 5 to $23 \mathrm{~km}$ depth in (a) Scenario 4 and (b) Scenario 6. Below $24 \mathrm{~km}$, the differential stress is tapered to zero in all scenarios. As shown for Scenario 4 here, the depth dependent $P_{f}$ in Scenarios 1-4 causes the shear and effective normal stresses to increase with depth. As shown for Scenario 6 here, a $P_{f}$ gradient that mirrors the lithostatic gradient in Scenarios 5-6 causes the shear and effective normal stresses to remain constant with depth. 

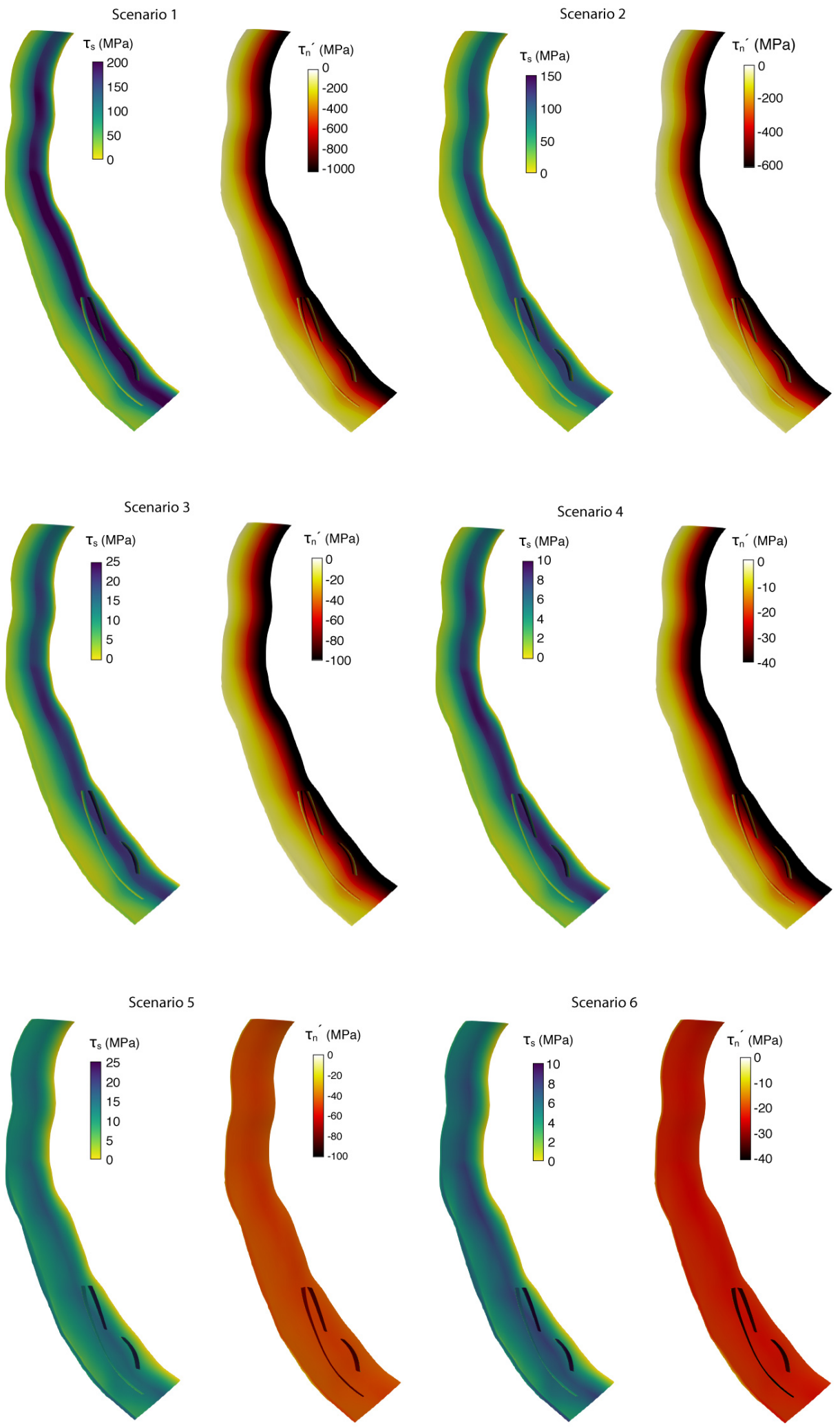

Figure 3. Initial shear traction $\left(\tau_{s}\right)$ and effective normal traction $\left(\tau_{n}^{\prime}\right)$ on the megathrust in Scenarios 1 to 6 . For each fault image, the shallowest part of the megathrust where it intersects the seafloor is on the left and the deepest part at $50 \mathrm{~km}$ depth is on the right. Note the depthdependent $\tau_{n}^{\prime}$ in scenarios 1 to 4 versus nearly constant $\tau_{n}^{\prime}$ in scenarios 5 and 6 . Both $\tau_{s}$ and $\tau_{n}^{\prime}$ vary with the non-planar fault geometry. 


\subsection{Failure and spontaneous propagation}

In all scenarios, dynamic earthquake rupture starts by forced nucleation in the southeastern corner of the fault at $30 \mathrm{~km}$ depth. Failure occurs when $\tau_{s}$ exceeds the static fault strength, $T_{f s}$, which is determined from the on-fault cohesion, $c$, and the product of the coefficient of static friction, $\mu_{s}$, and $\tau_{n}^{\prime}$ as (compression is negative):

$$
T_{f s}=c-\mu_{s} \tau_{n}^{\prime}
$$

$c$ is the strength of the fault in the absence of $\tau_{n}^{\prime}$ and is used as a proxy for near-trench behavior that we do not model explicitly here. We set $c=0.4 \mathrm{MPa}$ along most of the megathrust, but $c$ linearly increases from $0.4 \mathrm{MPa}$ at $10 \mathrm{~km}$ depth to $15 \mathrm{MPa}$ at the top of the fault. For further discussion of $c$, please see Appendix A5.

We assign $\mu_{s}=0.4$ in all scenarios. Borehole estimates of stress in upper crustal rocks suggest that rocks follow Byerlee's law with $\mu_{s}=0.6$ to 1.0 (Townend \& Zoback, 2004), while in stress and strength analyses of the megathrust that slipped in the 2011 Tohoku earthquake, Brodsky et al. (2020) use laboratory derived values of $\mu_{s}=0.24$ attributed to high clay content. Our choice of $\mu_{s}=0.4$ is motivated by the lithology of the shallow megathrust potentially characterized by high, clay-rich sediment input (Hüpers et al., 2017) progressively strengthened by dehydration and compaction near the megathrust. Setting the principal stress magnitudes relative to $\sigma_{v}^{\prime}$ as we do maintains the $\tau_{s} / \tau_{n}^{\prime}$ distribution on the megathrust across all scenarios, though this ratio varies across the megathrust (see Figure A1). This motivates our choice to keep $\mu_{s}$ constant across all scenarios, allowing us to focus on the effects of $P_{f}$ magnitude and gradient.

We apply a linear slip-weakening friction law (e.g., Andrews, 1976) to represent dynamic weakening of the fault after failure. $\mu_{s}$ decreases to the coefficient of dynamic friction, $\mu_{d}$, over the slip-weakening distance, $D_{c}$. After weakening, the dynamic strength of the fault during slip, $T_{f d}$, is given by:

$$
T_{f d}=-\mu_{d} \tau_{n}^{\prime}
$$

We assign $\mu_{d}=0.1$ and use a constant value of $D_{c}=0.8 \mathrm{~m}$. 
The rupture continues to propagate as long as $\tau_{s}$ locally exceeds $T_{f s}$ and the fault continues to slip as long as sufficient strain energy is available. Note that $\tau_{s}$ at the rupture front is typically higher than the initial $\tau_{s}$, so statically stronger parts of the fault may fail after the rupture initiates elsewhere.

\section{Results}

\subsection{Earthquake source characteristics}

Table 3 summarizes average characteristics of the earthquakes in each scenario. As pore fluid pressure, $P_{f}$, increases from low to very high, the moment magnitude $\left(M_{w}\right)$ decreases, as do mean cumulative slip, peak slip rate $(P S R)$, mean dynamic stress drop $\left(\Delta \tau_{s}\right)$ and rupture velocity $(V r)$. This reflects our here chosen set-up, in which both shear and effective normal tractions scale inversely with $P_{f} . M_{w}$ of the earthquakes in Scenarios 1 and 2 are unrealistically large and are described in Appendix A2. $M_{w}$ for the earthquakes in Scenarios 3 to 6 are reasonable for a rupture area the size of the Sumatra earthquake (Strasser et al., 2010), so we focus on the results for these four scenarios.

Videos of the slip rate evolving along the megathrust during each of these scenarios are available by link from Appendix A2. In all four scenarios, an initially crack-like rupture develops into sharp rupture pulses propagating along-arc and consisting of multiple rupture fronts, which are caused by reflected waves and head waves generated at structural interfaces and the complex free surface (Huang et al., 2014). We note that pulselike rupture here is due to geometric constraints (Weng \& Ampuero, 2019). Figure 4 compares slip, $P S R, \Delta \tau_{s}$ and $V r$ on the megathrust at the end of the earthquakes in scenarios 3-6.

The magnitude of pore fluid pressure, $P_{f}$, inversely affects average cumulative slip, while the way in which it is applied influences the slip distribution on the megathrust (Figure 4). As $P_{f}$ increases from high in Scenario 3 to very high in Scenario 4, mean slip decreases from $26 \mathrm{~m}$ to $8 \mathrm{~m}$. This is reflected in the decrease in earthquake moment magnitude from $M_{w} 9.3$ in Scenario 3 to $M_{w} 9.0$ in Scenario 4 . The slip is similarly distributed in both scenarios, with maximum slip in the middle of the fault in the down-dip direction. Slip is also highest in the center of the fault along strike. Likewise, as $P_{f}$ increases from high in Scenario 5 to very high in Scenario 6, mean slip decreases from $36 \mathrm{~m}$ to $10 \mathrm{~m}$ and moment magnitude decreases from $M_{w} 9.4$ to $M_{w}$ 9.1. Mean slip and $M_{w}$ are sim- 
Table 3. Earthquake characteristics averaged across the megathrust

\begin{tabular}{cccccc}
\hline Scenario & $M_{w}$ & $\operatorname{slip}(\mathrm{m})^{a}$ & mean $P S R(\mathrm{~m} / \mathrm{s})^{b}$ & mean $\Delta \tau_{s}(\mathrm{MPa})^{c}$ & mean $V r(\mathrm{~m} / \mathrm{s})^{d}$ \\
\hline 1 & 10.2 & 470 & 75 & 79 & 4765 \\
2 & 9.9 & 235 & 46 & 42 & 4246 \\
3 & 9.3 & 26 & 10 & 8 & 3025 \\
4 & 9.0 & 8 & 5 & 3 & 2370 \\
5 & 9.4 & 36 & 11 & 7 & 3203 \\
6 & 9.1 & 10 & 6 & 3 & 2624 \\
\hline
\end{tabular}

${ }^{a}$ mean cumulative slip $\quad{ }^{b}$ peak slip rate $\quad{ }^{c}$ dynamic stress drop ${ }^{d}$ rupture velocity

ilar in scenarios with the same $P_{f}$ levels (scenarios 3 and 5 , scenarios 4 and 6 ). However, in scenarios 5 and 6 , in which $P_{f}$ mirrors the lithostatic pressure gradient causing constant effective normal stress with depth, maximum slip is shifted up-dip relative to the locations of maximum slip in scenarios 3 and 4 . Slip to the trench only occurs in Scenario 5, and slip is limited at the trench in scenarios 3, 4 and 6 . We discuss this in Section 6.1 (see also Appendix A5).

As with cumulative slip, peak slip rate $P S R$ in these scenarios decreases as $P_{f}$ magnitude increases and the $P_{f}$ gradient influences its distribution along the megathrust. Mean $P S R$ is $10 \mathrm{~m} / \mathrm{s}$ in Scenario 3 and decreases to $5 \mathrm{~m} / \mathrm{s}$ in Scenario 4 . Mean PSR is $11 \mathrm{~m} / \mathrm{s}$ in Scenario 5 and decreases to $6 \mathrm{~m} / \mathrm{s}$ in Scenario 6 . scenarios 3 and 5 and scenarios 4 and 6 have similar mean PSR values, but maximum $P S R$ occurs below $35 \mathrm{~km}$ depth in scenarios 3 and 4 and above $15 \mathrm{~km}$ in scenarios 5 and 6 . Thus, relative to depthdependent normal stress, assumption of constant effective normal stress with depth, reflecting high $P_{f}$ increasing with the lithostatic gradient, shifts maximum PSR up-dip (Figure 4). In addition, more of the megathrust experiences high PSR in Scenario 6 relative to Scenario 4, though the maximum values are lower in Scenario 6 .

We measure the mean dynamic stress drop $\Delta \tau_{s}$ as the average change in shear traction, $\tau_{s}$, from the initial value to the dynamically reached value at the end of the earthquake. As for mean slip and $P S R, P_{f}$ has an inverse relationship with mean $\Delta \tau_{s}$. Mean $\Delta \tau_{s}$ is $8 \mathrm{MPa}$ in Scenario 3 and $7 \mathrm{MPa}$ in Scenario 5, and $3 \mathrm{MPa}$ in both scenarios 4 and 6. The distribution of $\Delta \tau_{s}$ varies with the $P_{f}$ gradient. In scenarios 3 and $4, \Delta \tau_{s}$ is larger along the deeper fault, reaching values of $15 \mathrm{MPa}$ and $7 \mathrm{MPa}$, respectively, below $30 \mathrm{~km}$ depth (Figure 4). In scenarios 5 and $6, \Delta \tau_{s}$ is relatively constant along the central fault in the down-dip direction. The highest values are farther up-dip near $20 \mathrm{~km}$ depth, at 

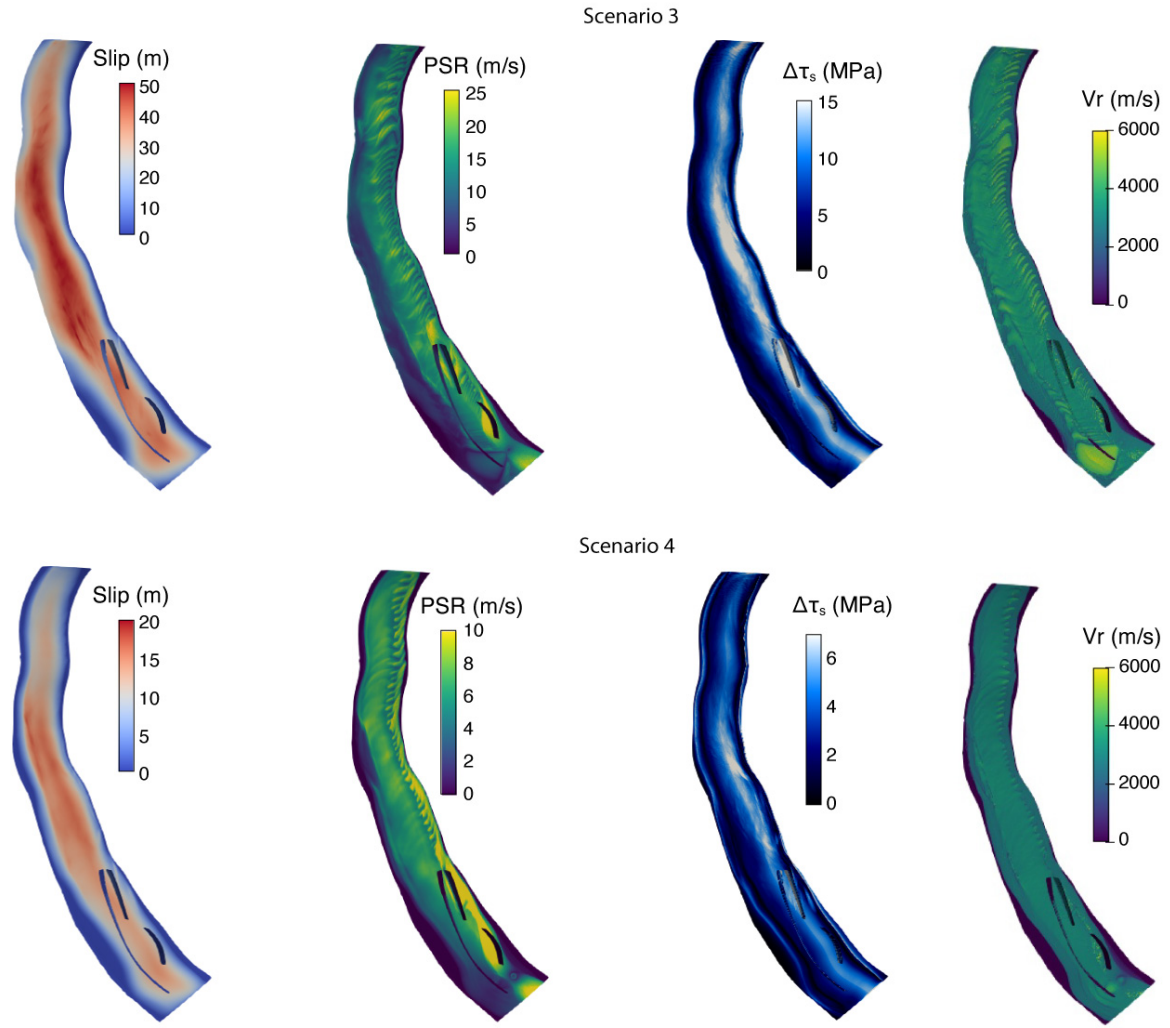

Scenario 4
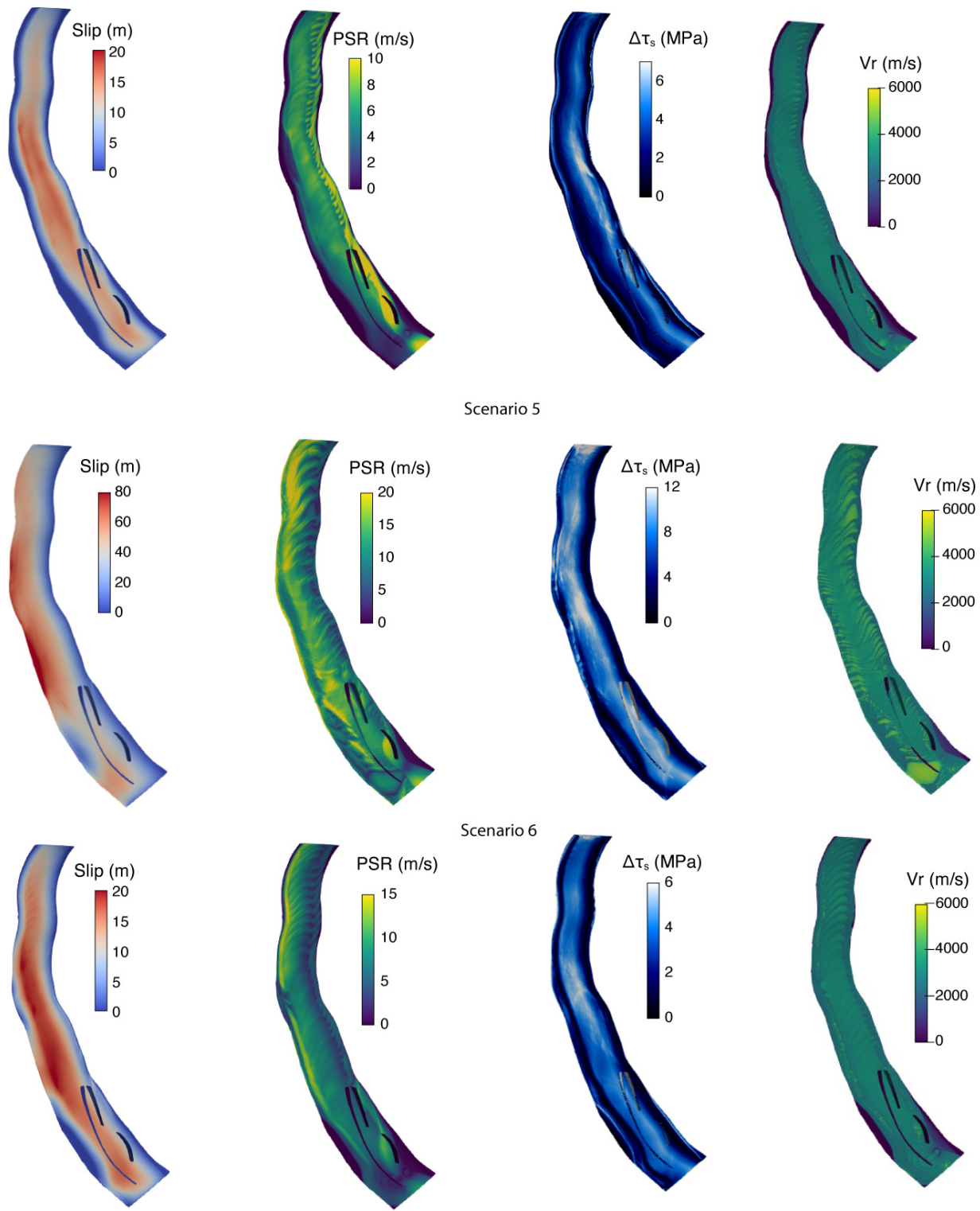

Figure 4. For Scenarios 3 to 6: cumulative slip, peak slip rate $(P S R)$, dynamic stress drop $\left(\Delta \tau_{s}\right)$, and rupture velocity $(V r)$ on the megathrust. For each fault image, the shallowest part of the fault is to the left and the deepest part (at $50 \mathrm{~km} \mathrm{depth)} \mathrm{is} \mathrm{to} \mathrm{the} \mathrm{right.} \mathrm{A} \mathrm{version} \mathrm{with}$ alternative colorbar limits that are set for comparison across scenarios is included as Figure A3. 
$12 \mathrm{MPa}$ and $5 \mathrm{MPa}$ in these scenario, respectively. In all scenarios, $\Delta \tau_{s}$ is largest along the central portion of the fault along strike.

An increase in $P_{f}$ causes a decrease in average rupture velocity, $V r$, from $3025 \mathrm{~m} / \mathrm{s}$ in Scenario 3 to $2370 \mathrm{~m} / \mathrm{s}$ in Scenario 4 and from $3206 \mathrm{~m} / \mathrm{s}$ in Scenario 5 to $2624 \mathrm{~m} / \mathrm{s}$ in Scenario 6. Mean $V r$ is lower in Scenario 3 relative to Scenario 5, and lower in Scenario 4 relative to Scenario 6, suggesting that average $V r$ increases under conditions of constant versus depth-dependent effective normal stress. In all scenarios, average $V r$ is sub-Rayleigh relative to the lower velocity subduction channel surrounding the megathrust slip interface $\left(V_{s}=3500 \mathrm{~m} / \mathrm{s}\right.$, Table 1$)$. While $V r$ is below Rayleigh wave speed across most of the megathrust in all scenarios, exceptions of supershear rupture appear i) propagating up-dip from the hypocenter at close to P-wave speed triggered by energetic nucleation and ii) in form of localized and relatively slow supershear fronts excited before the sub-Rayleigh rupture front at several isolated locations. At these isolated locations, in Scenario 5 where $V r$ is highest out of all scenarios, $V r \approx 70 \%$ of $\mathrm{P}$-wave speed. Thus, $V r$ exceeds the S-wave speed, but remains far lower than the $\mathrm{P}$-wave speed in these scenario ruptures in general. This agrees with inferences and modeling for earthquake rupture in damaged fault zones (e.g., Bao et al., 2019). In contrast to the other earthquake characteristics, there is little variation in the distribution of $V r$ with $P_{f}$ gradient.

\subsection{Post-earthquake stress field}

The dynamic rupture model utilized in these scenarios permits investigation of the post-earthquake absolute stress field. We compare principal stress orientations and relative magnitudes along a cross-section of the central part of the rupture in scenarios 3 to 6 (see inset in Figure 5a). Figure 5a shows the orientations of the principal stresses ( $\sigma_{3}<\sigma_{2}<\sigma_{1}$, compression is negative) before the earthquake for all scenarios and Figure 5b shows the orientations after dynamic earthquake rupture in Scenario 4. The post-earthquake stress orientations for scenarios 3, 5 and 6 are shown in Figure A4. We summarize the post-earthquake stress orientations for all scenarios in stereonets focused on the hanging wall and footwall regions close to the fault in Figure 5c. We compare the mean orientations of the principal stresses in the hanging wall before and after the earthquake in Table 4 and report average rotations in Table 5. We note that the reported changes in orientation from before to after the earthquake are "apparent" rotations and do not account for a principal stress switching locations with another principal stress due to mag- 

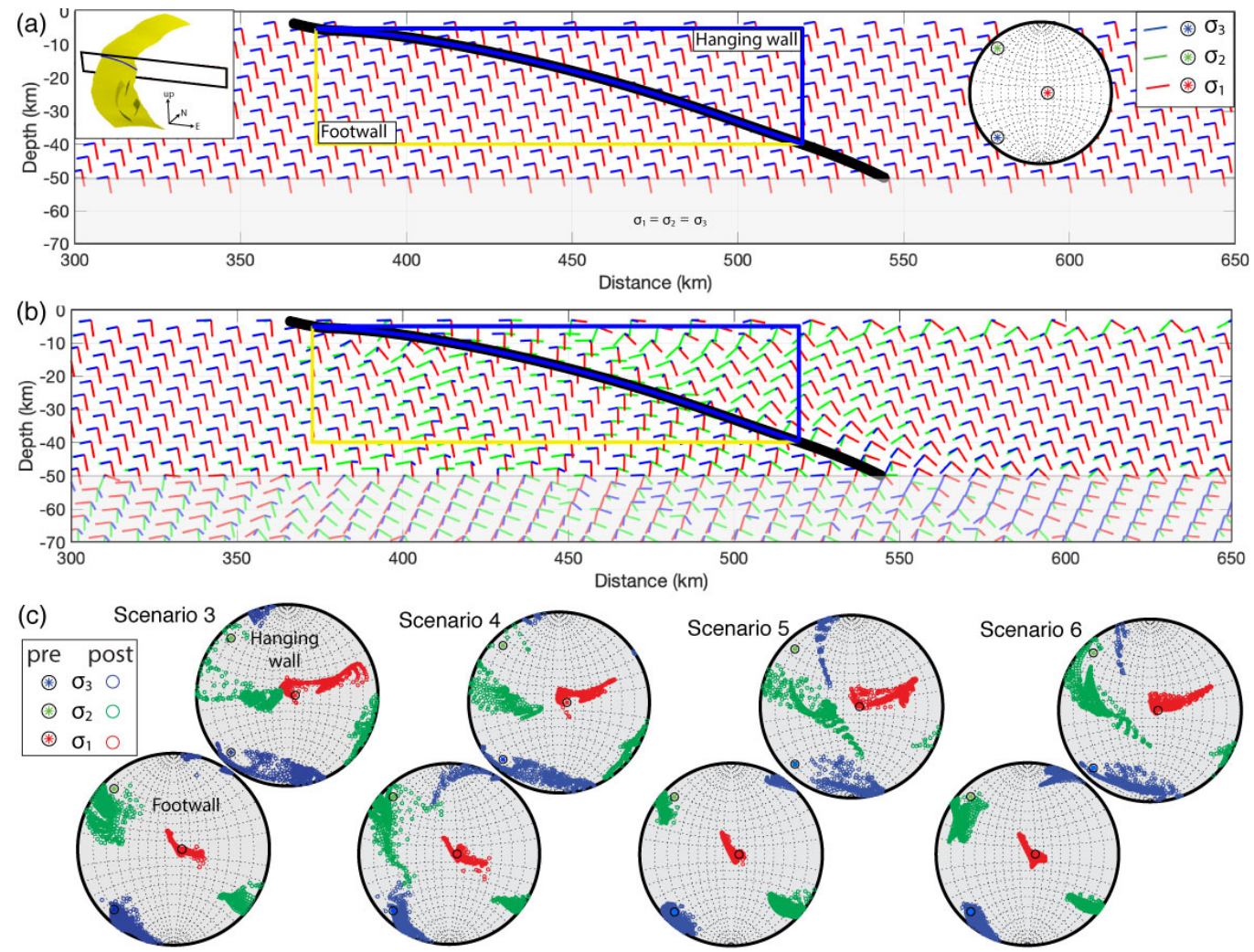

Figure 5. (a) Orientations of the principal stresses before the earthquake for all scenarios. $\sigma_{2}$ vectors are behind $\sigma_{3}$ vectors. The black line is the megathrust profile. Blue and yellow lines outline the hanging wall and footwall regions analysed in (c). The left inset shows the cross-section location through the model volume near the fault (yellow). The right inset shows the stereonet of pre-earthquake principal stresses. (b) Orientations after the dynamic earthquake rupture in Scenario 4. (c) Stereonets of post-earthquake principal stress orientations in Scenario 4. Hanging wall and footwall regions are outlined in (a) and (b).

nitude changes. These apparent rotations are similar to rotations inferred from earthquake data, for which information is available only before and after an earthquake.

In all scenarios, the principal stresses rotate more in the hanging wall than in the footwall. In the hanging wall across all scenarios, the trend of $\sigma_{3}$ rotates counterclockwise by $28-40^{\circ}$ toward parallel with megathrust strike, while its plunge remains shallow at $7-9^{\circ} . \sigma_{2}$ rotates counterclockwise by $38-63^{\circ}$ and its plunge steepens by $15-37^{\circ} . \sigma_{1}$ rotates counterclockwise by $20-42^{\circ}$ and its plunge shallows by $14-38^{\circ}$ from near-vertical $\left(80^{\circ}\right)$ to moderate $\left(42-66^{\circ}\right)$.

In all scenarios, $\sigma_{2}$ and $\sigma_{3}$ have similar mean apparent rotations and rotate more than the minimum principal stress, $\sigma_{1}$. The mean principal stress rotations in the hang- 
Table 4. Pre- and post-earthquake mean principal stress orientations ${ }^{a}$

\begin{tabular}{cccccccc}
\hline Scenario & & $\sigma_{3}$ trend & plunge & $\sigma_{2}$ trend & plunge & $\sigma_{1}$ trend & plunge \\
\hline all & pre & $225 \pm 0^{\circ}$ & $7 \pm 0^{\circ}$ & $315 \pm 0^{\circ}$ & $7 \pm 0^{\circ}$ & $90 \pm 0^{\circ}$ & $80 \pm 0^{\circ}$ \\
\hline 3 & post & $184 \pm 41^{\circ}$ & $7 \pm 5^{\circ}$ & $258 \pm 56^{\circ}$ & $36 \pm 26^{\circ}$ & $53 \pm 34^{\circ}$ & $51 \pm 24^{\circ}$ \\
4 & post & $193 \pm 33^{\circ}$ & $7 \pm 5^{\circ}$ & $253 \pm 60^{\circ}$ & $22 \pm 18^{\circ}$ & $48 \pm 37^{\circ}$ & $66 \pm 16^{\circ}$ \\
\hline 5 & post & $197 \pm 64^{\circ}$ & $9 \pm 11^{\circ}$ & $257 \pm 33^{\circ}$ & $44 \pm 20^{\circ}$ & $70 \pm 16^{\circ}$ & $42 \pm 19^{\circ}$ \\
6 & post & $197 \pm 35^{\circ}$ & $9 \pm 6^{\circ}$ & $277 \pm 40^{\circ}$ & $22 \pm 16^{\circ}$ & $68 \pm 20^{\circ}$ & $64 \pm 16^{\circ}$ \\
\hline
\end{tabular}

${ }^{a}$ calculated in vertical slice and in hanging wall only (see Figure 5)

Table 5. Apparent mean coseismic principal stress rotations ${ }^{a}$

\begin{tabular}{cccc}
\hline Scenario & $\sigma_{3}$ rotation & $\sigma_{2}$ rotation & $\sigma_{1}$ rotation \\
\hline 3 & $46 \pm 18^{\circ}$ & $50 \pm 20^{\circ}$ & $34 \pm 20^{\circ}$ \\
4 & $36 \pm 18^{\circ}$ & $38 \pm 18^{\circ}$ & $21 \pm 11^{\circ}$ \\
\hline 5 & $55 \pm 16^{\circ}$ & $58 \pm 17^{\circ}$ & $39 \pm 17^{\circ}$ \\
6 & $36 \pm 18^{\circ}$ & $36 \pm 20^{\circ}$ & $19 \pm 14^{\circ}$ \\
\hline${ }^{2}$ calculated in vertical slice through hanging wall only (see Figure 5)
\end{tabular}

ing wall summarized in Table 5 vary with the magnitude of pore fluid pressure, $P_{f}$. As $P_{f}$ increases from Scenario 3 to Scenario 4 and from Scenario 5 to Scenario 6, mean rotations of each principal stress decrease in accordance with decreasing stress drop. Scenarios 4 and 6 have very similar apparent rotations for each principal stress, suggesting that the choice of $P_{f}$ gradient does not affect the amount of rotation when the $P_{f}$ magnitude is very high ( $97 \%$ of the lithostatic pressure). This similarity does not hold between Scenario 3 and Scenario 5, as mean rotations in Scenario 5 are the largest of all scenarios. We attribute this to the high fault slip at the trench in Scenario 5.

To better understand the post-earthquake stress field, we also consider the effective principal stress magnitudes relative to one another. This is important to the stress rotation analysis, because magnitudes of two principal stresses that move closer to one another approach the condition for switching orientations, allowing for a larger amount of heterogeneity in the post-earthquake stress field. Figure 6 shows the maximum differential stress, $\sigma_{d 13}^{\prime}=\sigma_{1}^{\prime}-\sigma_{3}^{\prime}$, before and after the dynamic earthquake ruptures in scenarios 3 to 6 . Prior to each earthquake, the distributions of $\sigma_{d 13}^{\prime}$ depend on the gradient in $P_{f}$. Scenarios 3 and 4 have the same depth-dependent pattern of $\sigma_{d 13}^{\prime}$, but the maximum $\sigma_{d 13}^{\prime}$ values in each scenario differ by up to $30 \mathrm{MPa}$. Similarly, scenarios 5 and 6 have the same pattern, which shows relatively constant values to $25 \mathrm{~km}$ depth before 
Table 6. Differential stress before and after the earthquake ${ }^{a}$

\begin{tabular}{ccccccc}
\hline Scenario & $\sigma_{d 13}^{\prime}$ pre $^{b}$ & $\sigma_{d 13}^{\prime}$ post & $\sigma_{d 12}^{\prime}$ pre & $\sigma_{d 12}^{\prime}$ post & $\sigma_{d 23}^{\prime}$ pre & $\sigma_{d 23}^{\prime}$ post \\
\hline 3 & $34 \pm 14$ & $27 \pm 10$ & $17 \pm 7$ & $15 \pm 7$ & $17 \pm 7$ & $12 \pm 4$ \\
4 & $15 \pm 6$ & $12 \pm 5$ & $7 \pm 3$ & $7 \pm 3$ & $7 \pm 3$ & $5 \pm 2$ \\
\hline 5 & $42 \pm 5$ & $31 \pm 5$ & $21 \pm 3$ & $18 \pm 7$ & $21 \pm 3$ & $12 \pm 5$ \\
6 & $20 \pm 2$ & $14 \pm 4$ & $10 \pm 1$ & $9 \pm 2$ & $10 \pm 1$ & $5 \pm 3$ \\
\hline
\end{tabular}

${ }^{a}$ calculated in vertical slice through hanging wall only (see Figure 5)

${ }^{b}$ maximum differential stress, $\sigma_{d 13}^{\prime}=\sigma_{1}^{\prime}-\sigma_{3}^{\prime}(\mathrm{MPa})$

tapering begins, but the maximum $\sigma_{d 13}^{\prime}$ values in each scenario differ by up to $20 \mathrm{MPa}$. Table 5 summarizes the mean values of all three differential stresses in the hanging wall: $\sigma_{d 13}^{\prime}, \sigma_{d 12}^{\prime}=\sigma_{1}^{\prime}-\sigma_{2}^{\prime}$ and $\sigma_{d 23}^{\prime}=\sigma_{2}^{\prime}-\sigma_{3}^{\prime}$. As pore fluid pressure increases from Scenario 3 to Scenario 4 and from Scenario 5 to Scenario 6 , pre-earthquake $\sigma_{d 13}^{\prime}$ averages in the hanging wall decrease by $\approx 20 \mathrm{MPa}$. In each scenario, $\sigma_{d 12}^{\prime}$ equals $\sigma_{d 23}^{\prime}$ before the earthquake, as $\sigma_{2}$ is initially set to be halfway between $\sigma_{3}$ and $\sigma_{1}$. The magnitudes of these differential stresses differ from Scenario 3 to Scenario 4 and from Scenario 5 to Scenario 6 by $\approx 10 \mathrm{MPa}$.

In the plots of the post-earthquake $\sigma_{d 13}^{\prime}$ distributions in Figure 6 , contours indicate the amount and direction (increase or decrease) of the change in $\sigma_{d 13}^{\prime} . \sigma_{d 13}^{\prime}$ decreases in the footwall in all scenarios along the central fault, but increases below the bottom of the fault. $\sigma_{d 13}^{\prime}$ decreases in the hanging wall in all scenarios, except near the end of the fault at depth. Decreases in $\sigma_{d 13}^{\prime}$ in the hanging wall are larger in scenarios 3 and 5 , reaching $15 \mathrm{MPa}$ and above over larger areas near the megathrust, corresponding to the larger slip in these scenarios relative to scenarios 4 and 6 , respectively. Decreases in $\sigma_{d 13}^{\prime}$ reach $10 \mathrm{MPa}$ in scenario 4 and $5 \mathrm{Mpa}$ in scenario 6 . In all scenarios, there are larger changes in average $\sigma_{d 23}^{\prime}$ than in average $\sigma_{d 12}^{\prime}$ due to the larger coseismic decrease in the magnitude of $\sigma_{3}^{\prime}$ relative to the decreases in $\sigma_{1}^{\prime}$ and $\sigma_{2}^{\prime}$ (Table 5). The closeness of $\sigma_{2}^{\prime}$ and $\sigma_{3}^{\prime}$ before the earthquake therefore controls the amount of apparent post-seismic stress rotation here, and how likely these two principal stresses are to switch locations. In contrast, $\sigma_{2}^{\prime}$ and $\sigma_{1}^{\prime}$ have less apparent rotation and are less likely to switch locations. 
(a)
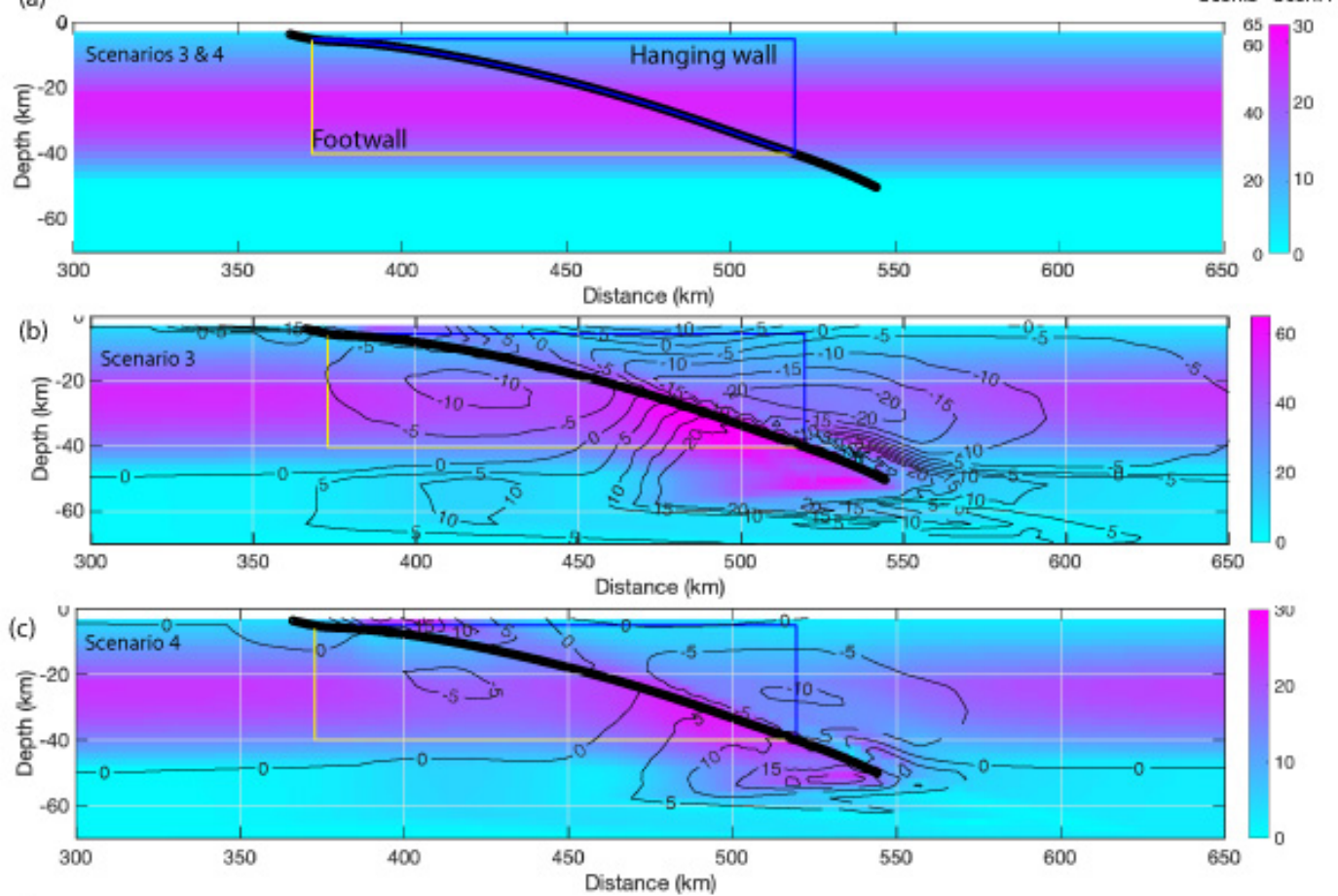

(d)

Scen. 5 Scen. 6
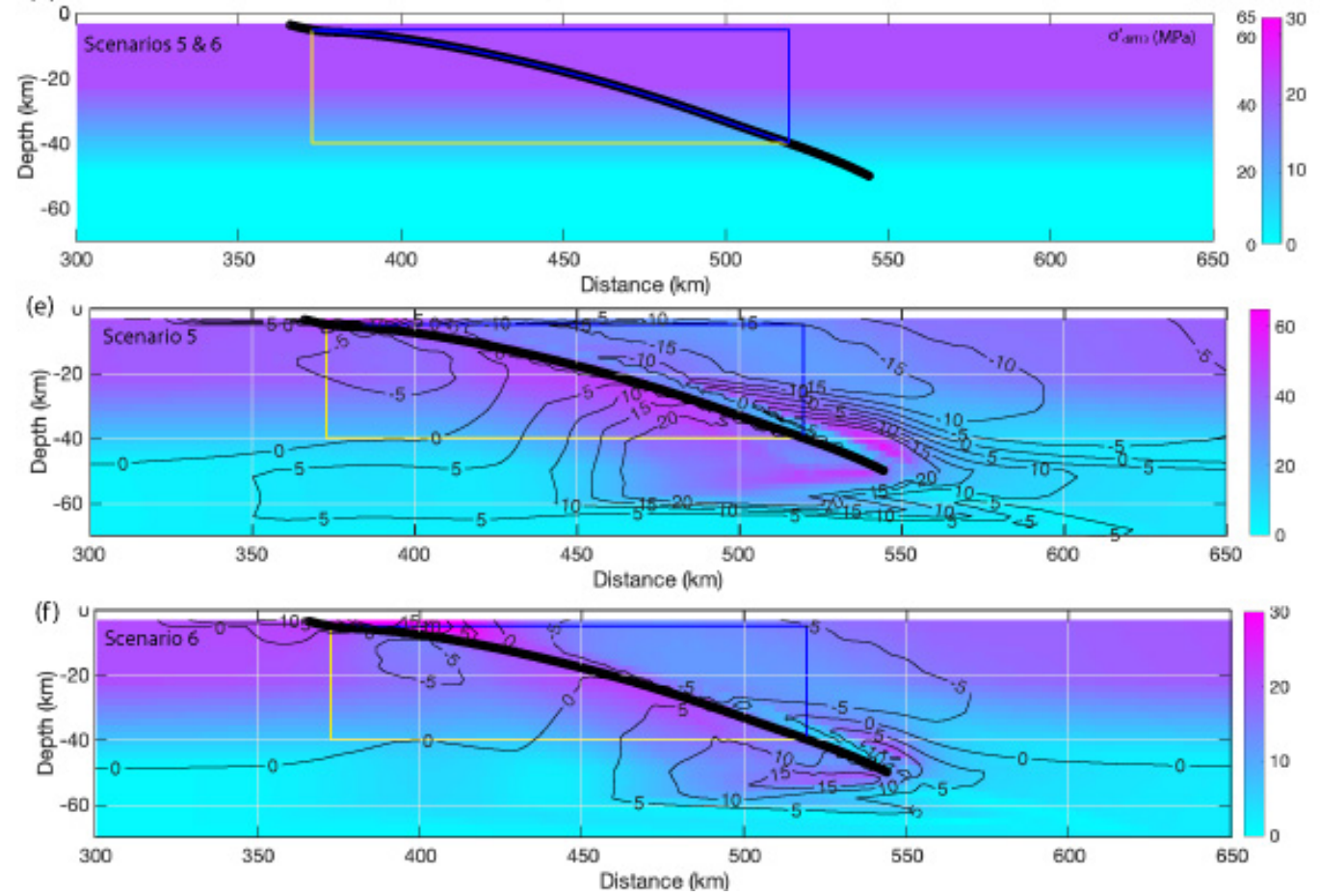

Figure 6. Cosesimic change in maximum effective differential stress $\left(\sigma_{d 13}^{\prime}\right)$ (a) before the earthquake in scenarios 3 and 4, (b) after the earthquake in Scenario 3, (c) after the earthquake in Scenario 4, (d) before the earthquake in scenarios 5 and 6, (e) after the earthquake in Scenario 5, and (f) after the earthquake in Scenario 6. Contours show change in $\sigma_{d 13}^{\prime}$ from pre- to post-earthquake. Location is as shown in inset in Figure 5. 


\section{Discussion}

We present 6 earthquake scenarios that vary in $P_{f}$ magnitude and gradient in order to explore the dynamic effects of different coseismic $P_{f}$ levels and distributions in subduction zones. The model structure and input are consistent with conditions for the 2004 Sumatra-Andaman earthquake, so we first discuss how the scenario earthquakes reflect observations of that event, as well as more general observations of earthquakes along megathrusts. Then, we discuss inferences from these scenarios relevant to fault mechanics. We also analyze further the stress rotations from before to after the these scenario earthquakes and compare these to observations following the 2004 Sumatra earthquake.

\subsection{Earthquake characteristics}

To first order, scenarios 3 and 6 produce earthquakes with moment magnitudes similar to those inferred for the Sumatra earthquake of $M_{w} 9.1$ to 9.3 (Shearer \& Bürgmann, 2010), while the Scenario 4 earthquake is just below this range at $M_{w} 9.0$ and the Scenario 5 earthquake is just above this range at $M_{w} 9.4$ (Table 3). Maximum slip values from kinematic source inversions compiled by Shearer and Bürgmann (2010) range up to a maximum value of $\approx 35 \mathrm{~m}$, suggesting that the slip in the Scenario 5 earthquake, which averages $36 \mathrm{~m}$, is too large. Seno (2017) estimates a mean stress drop of $3 \mathrm{MPa}$ for this earthquake, which is matched by those for scenarios 4 and 6 . In contrast, scenarios 3 and 5 have mean dynamic stress drops that are more than twice this value. The mean rupture velocities in scenarios 4 and 6 , respectively $2370 \mathrm{~m} / \mathrm{s}$ and $2624 \mathrm{~m} / \mathrm{s}$, are similar to the rupture velocity of $2500 \mathrm{~m} / \mathrm{s}$ inferred by Ammon et al. (2005) for the 2004 earthquake. In contrast, scenarios 3 and 5 both have mean $V r$ exceeding $3000 \mathrm{~m} / \mathrm{s}$.

Seno (2017) estimates a subducted sediment thickness of $1.57 \pm 0.12 \mathrm{~km}$ near Simeulue, in the southern region of the 2004 earthquake, which is relatively high compared with other subduction zones. Correlation between subducted sediment thickness, stress drop and pore fluid pressure (Seno, 2017) suggests that $P_{f}$ should be high and stress drop should be low, as in both scenarios 4 and 6 . This analysis renders scenarios 4 and 6 as preferred, and Scenario 6 emerges as the one that best matches observations, as Scenario 4 has lower slip that results in a $M_{w} 9.0$ event. 
The good performance of both scenarios 4 and 6 relative to observations of the 2004 Sumatra earthquake suggests that megathrust earthquakes may operate coseismically under conditions of low shear and effective normal tractions that result from very high fluid pressures. Scenarios 4 and 6 both have very high $P_{f}$, but differ in the way that $P_{f}$ is acting on the curved fault system. In Scenario $4, P_{f}$ follows a gradient at $97 \%$ of the lithostatic stress and $\tau_{n}^{\prime}$ increases with depth. In Scenario $6, P_{f}$ is also $97 \%$ of the lithostatic stress, but maintains a constant difference to the lithostatic stress, and $\tau_{n}^{\prime}$ is close to constant with depth along most of the megathrust. Although comparison with observations of the 2004 earthquake cannot conclusively differentiate between these two scenarios, Scenario 6 reflects more plausible conditions: if $P_{f}$ is very high, then theoretically, effective normal stress is expected to be constant near the megathrust (Rice, 1992).

These scenarios also are representative of variable conditions that may be present along a single megathrust, due to spatial variations in $P_{f}$ magnitude and/or gradient. Such variations in $P_{f}$ are one possible mechanism of conceptual seismic asperities, inducing heterogeneity in dynamic fault motion (e.g. Bürgmann, 2018). Sediments and high $P_{f}$ have been proposed as important mechanisms aiding stable sliding along geometric, frictional and rheological barriers, while thermal pressurization may provide a less effective mechanism for stress-roughening slip events (e.g. Gabriel et al., 2020). Our presented scenarios may serve as building blocks for future along-arc heterogeneous models. For example, we find that very high $P_{f}$ leading to constant effective normal stress with depth produces a stress drop on the megathrust that is nearly constant with depth and pushes peak slip rate up-dip on the megathrust. Also, earthquake magnitude and mean cumulative slip are larger for an equal or lower mean stress drop under these conditions. For a given subduction zone or megathrust event, detailed conditions may be constrained by geodetic, geological, or tsunami observations (e.g. Ulrich et al., 2020).

High or very high pore fluid pressure that causes $P_{f}$ to follow the lithostatic pressure results in depth-constant effective normal stress and favours higher slip at shallower depths, thus increasing the importance of near-trench strength and constitutive behavior. Widespread and high amplitude slip to the trench only occurs in Scenario 5, and slip is limited at the trench in scenarios 3,4 and 6 . In all scenarios, near-trench behavior is influenced by the choice of on-fault cohesion, $c$, which is used as a proxy for near-trench behavior that we do not model explicitly here, such as velocity-strengthening during slip in shallow sediments (e.g. Kaneko et al., 2008) and the energy lost to rock yielding around 
the megathrust (off-fault plasticity, e.g. Gabriel et al., 2013). $c$ is the same in all scenarios, but its relative contribution to the static fault strength increases as $P_{f}$ increases and $\tau_{n}^{\prime}$ decreases (Eq.1, Figure 3). Models that aim to capture natural co-seismic near-trench processes (e.g. Ulrich et al., 2020) can further discriminate governing factors of near-trench behavior (see also Appendix A5).

Next, we look to general observations of megathrust stress drop and geometry to further decipher between scenarios. Bilek and Lay (2018) reports a very weak correlation between stress drop and depth. However, Allmann and Shearer (2009) report depthdependent stress drops when data is considered separately by region. Uchide et al. (2014) find increasing stress drop from $30-60 \mathrm{~km}$ depth in an analysis of smaller events occurring before the 2011 Tohoku earthquake, which may reflect down-dip stress drop variation with depth of a large megathrust event. We determine the dynamic stress drop on the megathrust in each scenario, which differs slightly from these observationally inferred values. Stress drop differs along the megathrust by up to $7 \mathrm{MPa}$ in scenarios 4 and 6 and $15 \mathrm{MPa}$ in scenarios 3 and 5. Stress drop varies more with depth in scenarios 3 and 4, due to the depth-dependent effective normal traction resulting from the depth-dependent $P_{f}$ (Figure 4). Thus, low dependence of stress drop on depth is most consistent with very high $P_{f}$ that follows the lithostatic gradient (Scenario 6). A correlation between stress drop and depth is more consistent with $P_{f}$ that increases with depth (Scenario 3). Should these end-member conditions be present in different locations along a single megathrust, deciphering a dependence of stress drop on depth will be difficult.

When high $P_{f}$ mirrors the lithostatic gradient, the effective normal stress is constant and the effective normal tractions are relatively constant. However, variations still arise due to complex fault geometry. Bletery et al. (2016) find a link between low megathrust curvature and the occurrence of large earthquakes. They attribute the location and extent of the 2004 Sumatra earthquake rupture to a region of relatively homogeneous megathrust shear strength. Homogeneity of shear and normal traction is promoted by high $P_{f}$ leading to relatively constant normal stress with depth. Such conditions may emphasize the influence of geometry on earthquake behavior, as geometry becomes the main control on shear traction variation on the megathrust. We also note that the shear strength of a megathrust may be more homogeneous under conditions of very high $P_{f}$, and hence may be more likely to be exceeded simultaneously over large areas. Both effects may be explored in future work focusing on variations in megathrust geometry com- 
plexity and cycles of fault slip and by relaxing our assumption of constant shear to normal stress ratio.

\subsection{Inferences from these scenarios relevant to fault mechanics}

Here, we consider the scenarios in light of inferences about fault mechanics, beginning with the initial shear traction $\left(\tau_{s}\right)$ on the fault, then discussing effective normal traction $\left(\tau_{n}^{\prime}\right)$ magnitudes and how they vary with depth.

From force-balance studies, Lamb (2006) finds that the crust above 7 out of 9 studied subduction zones sustains an average $\tau_{s}$ of 7-15 MPa. This includes Sumatra, with an average $\tau_{s}$ of $15.2 \mathrm{MPa}$ (Lamb, 2006, Table 5), which is similar to the mean $\tau_{s}$ prior to rupture on the megathrust in scenarios 3 and 5. Brodsky et al. (2020, Fig. 6) constrain $\tau_{s}$ on the shallow part of the Tohoku megathrust prior to the 2011 Tohoku earthquake at $\approx 1.7 \mathrm{MPa}$ using a friction coefficient derived from low-velocity friction experiments. Yao and Yang (2020) find the shear strength of the megathrust that ruptured in the 2012 Nicoya earthquake to be less than 7.5 MPa on average. In combination with observed low stress drops of subduction megathrust events (Gao \& Wang, 2014), low dynamic shear stresses during earthquake rupture (e.g. less than $1 \mathrm{MPa}$, Choy \& Boatwright, 1995) also support low $\tau_{s}$ on megathrusts prior to earthquakes, although this may include additional weakening from a variety of dynamic effects (Gao \& Wang, 2014).

In this suite of six scenarios, more reasonable earthquakes emerge at higher coseismic $P_{f}$ magnitudes and average initial $\tau_{s}$ values in scenarios 3 to 6 range from 5 to 11 MPa (Table 2). Thus $P_{f}$ higher than approximately $93 \%$ of the lithostatic gradient is consistent with inferences of low initial shear stress on the megathrust. As suggested by the analysis in Section 6.1, scenarios 4 and 6 produce the most realistic earthquakes, supporting $P_{f}$ at $97 \%$ of the lithostatic stress and consistent with $\tau_{s}$ on the megathrust of 4-5 MPa. There are exceptions to inferences of low initial $\tau_{s}$, however. Lamb (2006, Table 5) estimates values of 18.3 and $36.7 \mathrm{MPa}$ on the Chile and Tonga megathrusts, respectively, while depth-dependence is inferred for the Tohoku and northern Hikurangi megathrusts with values ranging up to $80 \mathrm{MPa}$ (Gao \& Wang, 2014). These values are more consistent with scenarios 3 and 5 .

In studies inferring fault mechanical parameters (e.g. strength, friction coefficients, weakening distance), the vertical stress and the resulting $\tau_{n}^{\prime}$ on a megathrust often are 
determined assuming a hydrostatic, depth-dependent $P_{f}$ gradient (e.g. Di Toro et al., 2011; Fulton et al., 2013; Brodsky et al., 2020). This is appropriate if $P_{f}$ is interseismically low and interseismic fault conditions are of interest. However, very high coseismic $P_{f}$ leading to constant effective normal stress near the megathrust has important implications for coseismic estimates of these parameters.

We choose to vary both $\tau_{s}$ and $\tau_{n}^{\prime}$ from scenario to scenario while keeping $\tau_{s} / \tau_{n}^{\prime}$ and $\mu_{s}$ constant. In all scenarios, the megathrust is moderately strong, with a static friction coefficient of 0.4. However, the low shear strengths $\left(T_{f s}\right.$, Eq. 1$)$ of the megathrust in the preferred scenarios can be used to classify the megathrust as weak. The megathrust also is dynamically weak, with friction dropping to 0.1 during sliding. Alternatively, we could set $\tau_{s}$ to be the same across all scenarios, but change $\mu_{s}-\mu_{d}$ from scenario to scenario. This follows (Ulrich et al., 2019), who show that order-of-magnitude stress drop estimates can be derived a-priori as $R_{o p t}(1-\gamma) \sigma_{c}\left(\mu_{s}-\mu_{d}\right)$, with $\gamma$ the fluid pressure ratio between fluid pressure $P_{f}$ and lithostatic confining stress $\sigma_{c}$ and $R_{o p t}$ being the relative prestress ratio between fault stress drop and breakdown strength drop on a virtual, optimally oriented fault. The relative results of this alternative set of scenarios would not change in terms of static or dynamic shear strength or rupture characteristics, but the scenarios would be characterized differently in terms of $P_{f}$ and coseismic stress rotation (Ulrich et al., 2020). These conditions may be explored in future work.

In these scenarios, high $P_{f}$ leads to low maximum differential stress (and a low deviatoric stress magnitude) and therefore to low $\tau_{s}$ along the megathrust. However, low maximum differential stress (and a low deviatoric stress magnitude) can occur independently of $P_{f}$ and depending only on the relative magnitudes of the absolute principal stresses. We assume a least compressive principal stress, $\sigma_{1}$, in our scenarios that is close to the vertical (or lithostatic) stress, but the other two principal stresses are more difficult to constrain. $\sigma_{3}$ could vary from what we choose, which would then change $\tau_{s}$ on the megathrust as well as the average $\tau_{s}$ associated with a particular $P_{f}$. More complicated stress conditions also are likely. For example, we choose to set $\sigma_{2}$ midway between $\sigma_{1}$ or $\sigma_{3}$, but this is not necessarily the case in nature. In addition, principal stress magnitudes may vary in magnitude or orientation along the megathrust, both laterally and with depth. Past earthquakes may leave heterogeneous shear tractions on the megathrust and $P_{f}$ likely varies spatially in the vicinity of the megathrust (Heise et al., 2017). Close to the fault, there is field evidence of stress rotations within the damage zone that vary the princi- 
pal stress orientations from those in the remote field (Faulkner et al., 2006) and this condition is supported by theory (Rice, 1992). It will be interesting to relate stress complexity with $P_{f}$ and additional along-arc heterogeneity in future work.

\subsection{Off-fault results}

It has been suggested that principal stress rotations are promoted by complete or near-complete stress drops that permit principal stresses to swap orientations (Brodsky et al., 2017, 2020; Wang \& Morgan, 2019). However, by connecting 2D stress rotations to the ratio of stress drop over pre-earthquake deviatoric stress magnitude, Hardebeck (2012) shows that partial stress release may generate moderate rotations. Scenarios 3 and 5 experience the largest rotations, but have larger initial differential stresses and larger post-earthquake differential stresses as well. The larger rotations in these scenarios appear to scale with fault slip and stress drop, both of which are larger than in scenarios 4 and 6. Wang and Morgan (2019) attribute observed changes in stress orientations following the 2011 Tohoku earthquake to rapid weakening of a statically strong fault with $\mu_{s}$ in the range of $0.3-0.6$. This is supported by the scenarios presented here with high $P_{f}$, where the megathrust is statically strong in terms of its moderate value of $\mu_{s}=0.4$, but dynamically weak, in terms of its dynamic friction coefficient of $\mu_{d}=0.1$.

None of the scenarios results in a complete stress drop and yet we find that the postseismic stress field supports a variety of potential aftershock focal mechanisms. In all scenarios, $\sigma_{3}$ rotates toward parallel with megathrust strike and its plunge remains more or less unchanged, while the plunge of $\sigma_{2}$ increases and the plunge of $\sigma_{1}$ decreases. This post-seismic stress state supports a variety of aftershock mechanisms, including strikeslip faulting where $\sigma_{1}$ plunges more shallowly relative to $\sigma_{2}$, and reverse faulting where $\sigma_{2}$ plunges more shallowly relative to $\sigma_{1}$. Of $13 M_{w} 6$ or larger aftershocks with focal mechanisms solutions in the GCMT catalog (Ekström et al., 2012) occurring along the central rupture within five years of the 2004 Sumatra mainshock (through December 27 , 2009), 8 are reverse and 5 are strike-slip. We define the central rupture here as the region from $5^{\circ}$ to $9^{\circ}$ latitude, $91^{\circ}$ to $97.3^{\circ}$ longitude, and $0-50 \mathrm{~km}$ depth, corresponding to the location of the the slice in Figure 5 . Out of $125 M_{w} 5$ or larger aftershocks occurring within 1 month of the mainshock in the same region, 63 have strike-slip focal mechanisms, while 29 have reverse, 31 have normal mechanisms and 2 cannot be categorized. 
At Sumatra, Hardebeck (2012) finds rotations of the maximum compressive principal stress, which we call $\sigma_{3}$, relative to the megathrust and in the 2D plane perpendicular to the megathrust, to be up to $\approx 42^{\circ}$ and increasing from South to North. Along the central rupture (zone B in Hardebeck, 2012), average $\sigma_{3}$ rotation is $26 \pm 13^{\circ}$. The ratio of the mean earthquake stress drop to the magnitude of the deviatoric stress, $\Delta \tau_{s} / \sigma_{\text {dev }}$, can be estimated as a function of the pre-earthquake angle of $\sigma_{3}$ to the megathrust and its rotation (Hardebeck, 2012). At Sumatra specifically, Hardebeck (2012) finds that this ratio varies from 0.6 along the southern part of the rupture to 0.8 along the central and northern part of the rupture. This implies that $60-80 \%$ of the pre-earthquake deviatoric stress magnitude along the megathrust was relieved by the earthquake. The apparent rotations of $\sigma_{3}$ along the central rupture in these scenarios (Table 5) are of similar magnitudes to those determined from data (Hardebeck, 2012), ranging from $36^{\circ}$ to $55^{\circ}$, but are predominantly in the horizontal plane. We also find similar ratios of $\Delta \tau_{s}$ to $\sigma_{\text {dev }}$ in these scenarios, of 0.6 in Scenarios 4, 5 and 6 and of 0.7 in Scenario 3. We do not see correspondence between differences in $\Delta \tau_{s} / \sigma_{\text {dev }}$ and the amount of $\sigma_{3}$ rotation (Table 5 ), but note that this analysis is not directly comparable to the 2D analysis by Hardebeck (2012), as $\sigma_{3}$ rotates out of the plane perpendicular to the megathrust.

Post-earthquake stress and aftershock focal mechanism heterogeneity would be further promoted in a model incorporating a heterogeneous initial stress field. In these scenarios, the remote stress is used to set the tractions on the fault and the remote principal stress orientations are the same everywhere, so $P_{f}$ and the resulting effective stress field are the same on and off the megathrust before the earthquake. Similar on- and offfault stresses are not likely in nature. Away from the megathrust, secondary faulting, the earthquake history and material contrasts likely produce stress heterogeneities (I. v. Zelst et al., 2020). Heterogenity in the magnitude of the effective intermediate principal stress, $\sigma_{2}$ ', relative to the maximum and minimum effective principal stresses also would contribute to aftershock heterogeneity, by making it easier for different faulting regimes to be activated. For example, as we note in Section 5.2, the magnitude of $\sigma_{2}$ ' relative to the other two effective principal stresses controls the ability for $\sigma_{2}$ ' to switch places with $\sigma_{1}^{\prime}$ or $\sigma_{3}$ ', thus affecting postseismic stress rotations. In addition, dynamic effects that decouple conditions on and off the fault, such as thermal pressurization (Noda et al., 2009) during which $P_{f}$ increases rapidly due to reduced pore pressure diffusion in the fault zone during slip, may allow low effective normal tractions on the megathrust while different 
stresses persist away from the fault. Considering more complex initial stress conditions off the fault and decoupling on- and off-fault stresses are clear next steps for this work.

\section{Conclusions}

We highlight the effects of pore fluid pressure $\left(P_{f}\right)$ on megathrust effective stress state and earthquake dynamics using 3D geometrically complex high-performance computing enabled physics-based dynamic rupture models. The six scenarios presented, based on the $2004 M_{w} 9.1$ Sumatra-Andaman earthquake, have $P_{f}$ that varies from hydrostatic to lithostatic under different gradients that result in either depth-dependent or constant effective normal stress on the seismogenic part of the megathrust. As $P_{f}$ increases in these scenarios, moment magnitude, cumulative slip, peak slip rate, dynamic stress drop and rupture velocity all decrease. A $P_{f}$ gradient that mirrors the lithostatic pressure causes relatively constant effective normal traction on the megathrust, moves peak slip and peak slip rate up-dip, and produces a more constant stress drop across the megathrust. This is consistent with observations that the stress drops of smaller earthquakes in subduction zones are only weakly depth-dependent.

In comparison with observations, we identify two preferred scenarios that both support the presence of very high coseismic pore fluid pressure of $97 \%$ of the lithostatic pressure and have mean shear and effective normal tractions of 4-5 MPa and -22 MPa, respectively. The mean dynamic stress drop for these scenario earthquakes is $3 \mathrm{MPa}$ and the mean rupture velocity is $2400-2600 \mathrm{~m} / \mathrm{s}$, similar to observations of the 2004 SumatraAndaman earthquake. Although comparison with observations of the 2004 earthquake cannot conclusively differentiate between these two preferred scenarios, one of them reflects close to constant normal stress along the megathrust, which is the theoretically more plausible condition for very high $P_{f}$. On such weak megathrusts, in terms of the low static shear strength and low dynamic friction during rupture, near-trench strength and constitutive behavior are crucially important for megathrust hazard, as peak slip and peak slip rate occur at shallower depths. Mean apparent rotations of the principal stresses in the hanging wall decrease as $P_{f}$ magnitude increases, but do not vary with $P_{f}$ gradient. Scenarios with the largest rotations have larger initial differential stress and larger postearthquake differential stress as well. The larger rotations in these scenarios appear to scale with fault slip and stress drop. Along the central rupture, maximum compressive stress rotations in the hanging wall average $36 \pm 18^{\circ}$ toward trench-parallel in the two pre- 
ferred scenarios and the minimum principal stress rotates from near-vertical toward a shallower plunge. This post-earthquake stress field is consistent with the heterogeneous aftershocks observed following the Sumatra earthquake.

Variations in $P_{f}$ are one possible mechanism of conceptual seismic asperities, and our analysis may serve as guidance for future along-arc heterogeneous models. In addition, this work has implications for tsunami hazard, as $P_{f}$ is shown to influence the location of maximum slip and slip rate, which are pushed toward the surface when very high $P_{f}$ results in constant effective normal stress with depth near the megathrust.

\section{Appendix A Initial conditions for scenarios}

\section{A1 Initial conditions}

The relative prestress ratio, $R$, is the ratio of the fault stress drop $\left(\tau_{s}-T_{f d}\right)$ to the breakdown strength drop $\left(T_{f s}-T_{f d}\right)$, where $\tau_{s}$ is the initial shear traction, $T_{f s}$ is the static fault strength and $T_{f d}$ is the dynamic fault strength during sliding (Aochi \& Madariaga, 2003). $R$ varies along the megathrust with the non-planar fault geometry (Figure A1), but is nearly the same across all scenarios since $\tau_{s} / \tau_{n}^{\prime}$ is constant across all scenarios. The exception to this is with respect to the on-fault cohesion, $c . c$ is similar across all scenarios, but contributes differently to $T_{f s}$ in each scenario and this changes $R$ slightly from scenario to scenario, particularly at shallow depths (see also Appendix A5).

\section{A2 Earthquake results}

Slip, peak slip rate, dynamic stress drop and rupture velocity are shown in Figure A2 for Scenarios 1 and 2, which have low and moderate $P_{f}$, respectively.

\section{A3 Earthquake videos}

We provide animations showing absolute slip rate evolving along the megathrust during the earthquakes in scenarios 3 to 6 here: https://drive.google.com/drive/ folders/16eSMYsjQOADO2LMujKt7hEzvXsDcVaXj?usp=sharing. 

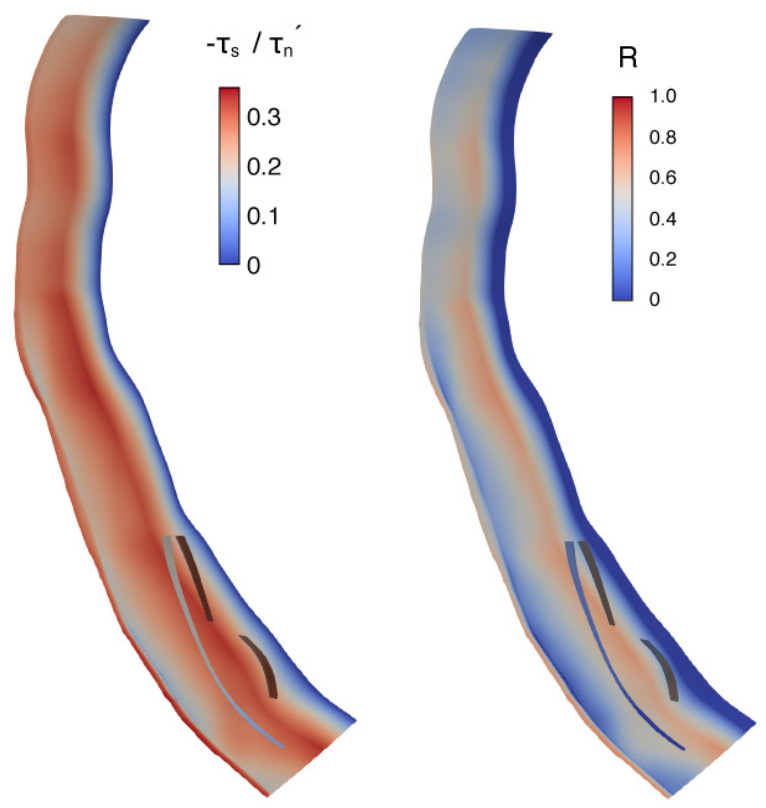

Figure A1. (left) The ratio of the initial shear traction to effective normal traction $\left(\tau_{s} / \tau_{n}^{\prime}\right)$ varies depending on the megathrust orientation relative to the local stress tensor, but the distribution on the megathrust is the same across all scenarios. (right) The prestress ratio, $\mathrm{R}$, is shown here for Scenario 4, but is similar in all scenarios.

\section{A4 Post-earthquake stress field}

Figure A4 shows the post-seismic stress field for all scenarios. While the rotation directions are similar in all scenarios, the amount of rotation is larger in scenarios 3 and 5 than in scenarios 4 and 6 . Stereonets are included in the main text (Figure 5).

\section{A5 Slip at the trench}

Slip proceeds to the trench in Scenario 5 and reaches maximum values there, which is clearly different from scenarios 3, 4 and 6 (Figure 4, Figure A3). A similar difference between shallow slip in Scenario 4 and Scenario 6 is also visible in Figure 4. These differences are due not only to $P_{f}$ magnitude and gradient, but also to the contribution of the applied on-fault cohesion, $c$, to static fault strength, $T_{f s}$. In all scenarios, $c$ is constant below $10 \mathrm{~km}$ depth and linearly increases toward the surface above, contributing to $T_{f s}$ according to Equation 1. The influence of $c$ on $T_{f s}$ increases as $P_{f}$ increases and $\tau_{n}^{\prime}$ decreases. As a result, closeness to failure varies near the seafloor in all scenarios. Fault strength is overcome at the trench only in Scenario 5, while slip is restricted along the top of the fault in scenarios 3,4 , and 6 . This contrast is important because it highlights 
Scenario 1
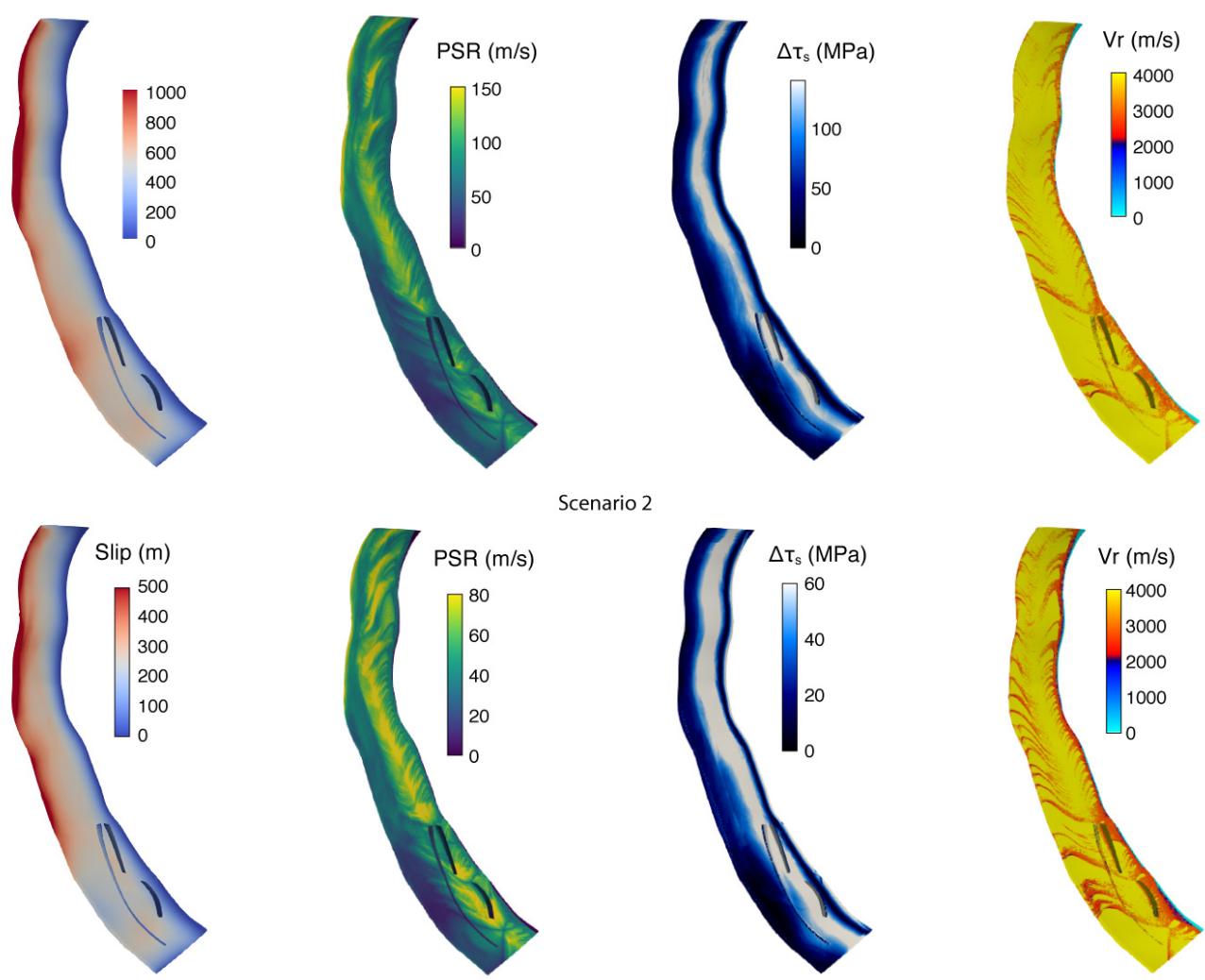

Figure A2. Cumulative slip, peak slip rate $(P S R)$, stress drop $\left(\Delta \tau_{s}\right)$ and rupture velocity $(V r)$ on the megathrust in Scenarios 1 and 2. For each fault image, the shallowest part of the fault (where it intersects the seafloor) is to the left and the deepest part (at $50 \mathrm{~km} \mathrm{depth}$ ) is to the right. 

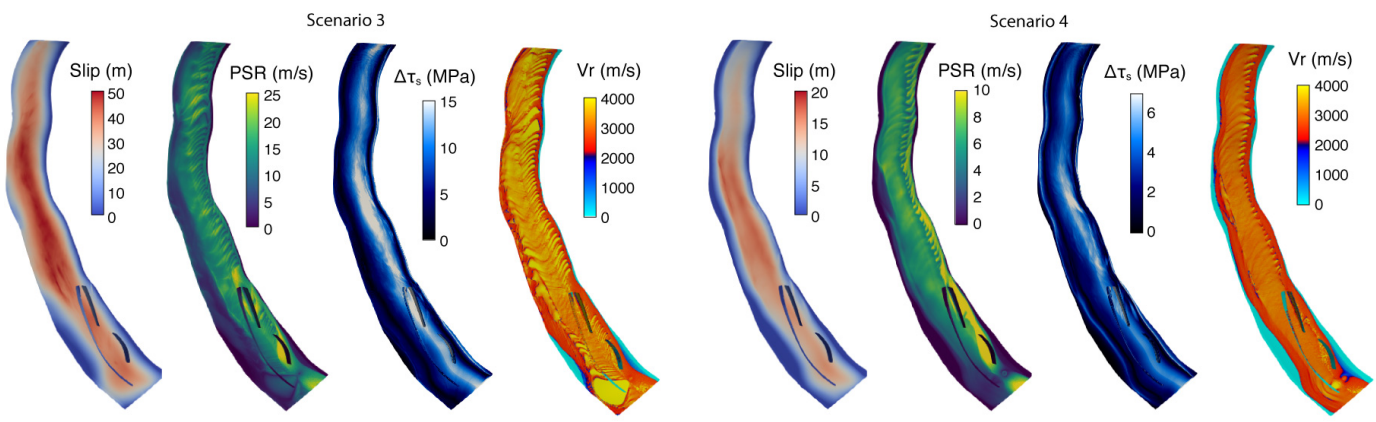

Scenario 5
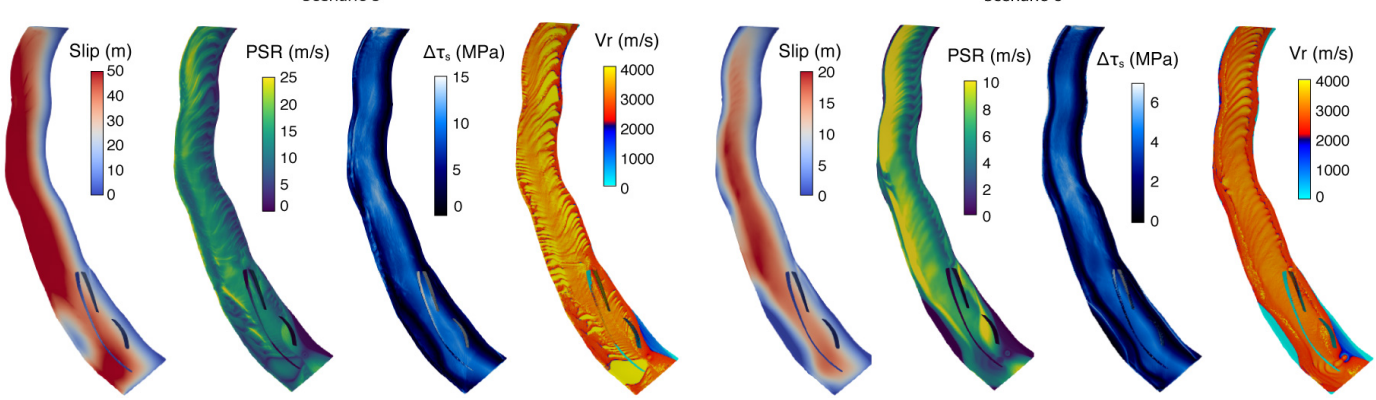

Figure A3. Cumulative slip, peak slip rate $(P S R)$, stress drop $\left(\Delta \tau_{s}\right)$ and rupture velocity $(V r)$ on the megathrust for scenarios 3-6 with alternative colorbars from Figure 4 that are better for comparison across scenarios. For each fault image, the shallowest part of the fault is to the left and the deepest part (at $50 \mathrm{~km}$ depth) is to the right.

both that the influence of $c$ on slip behavior at the trench increases as $P_{f}$ increases and $c$ becomes a larger component of $T_{f s}$, and that near-trench slip is encouraged by very high $P_{f}$ that causes conditions of constant $\tau_{n}^{\prime}$ along the megathrust and pushes maximum slip and slip rate closer to the trench. In these scenarios, $c$ is defined as the strength of the fault in the absence of $\tau_{n}$ (Equation 1) and is used as a proxy for near-trench behavior that we do not model explicitly here, including the energy lost to damage around the megathrust (off-fault plasticity, e.g. Gabriel et al., 2013) and velocity-strengthening of the fault in shallow sediments (e.g. Kaneko et al., 2008). Further study of slip behavior at the trench requires that the appropriate physical processes near the seafloor are incorporated into the model (e.g. Dunham et al., 2011; Ulrich et al., 2020). For example, Ulrich et al. (2020) incorporate slip strengthening and off-fault plasticity of lithified shallow sediments into coupled earthquake-tsunami models of the 2004 Sumatra earthquake and Indian Ocean tsunami to study near-trench slip, seafloor displacement and tsunami genesis using a coupled tsunami model. 


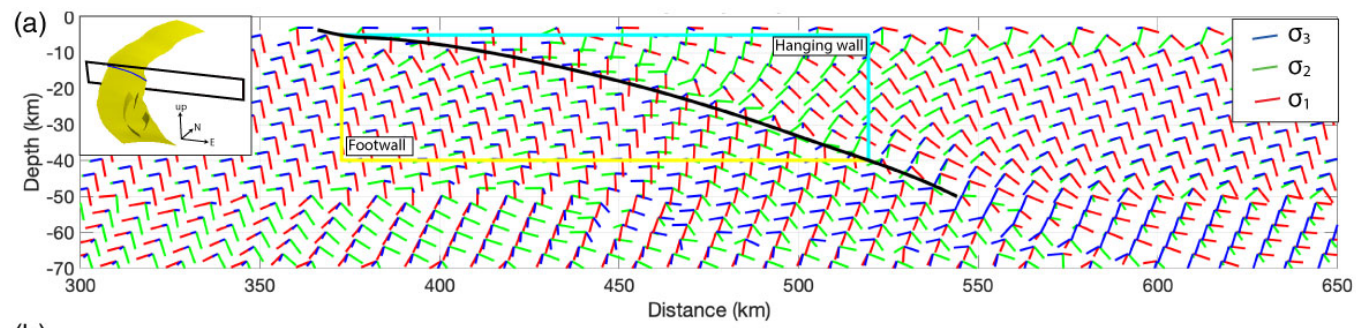

(b)
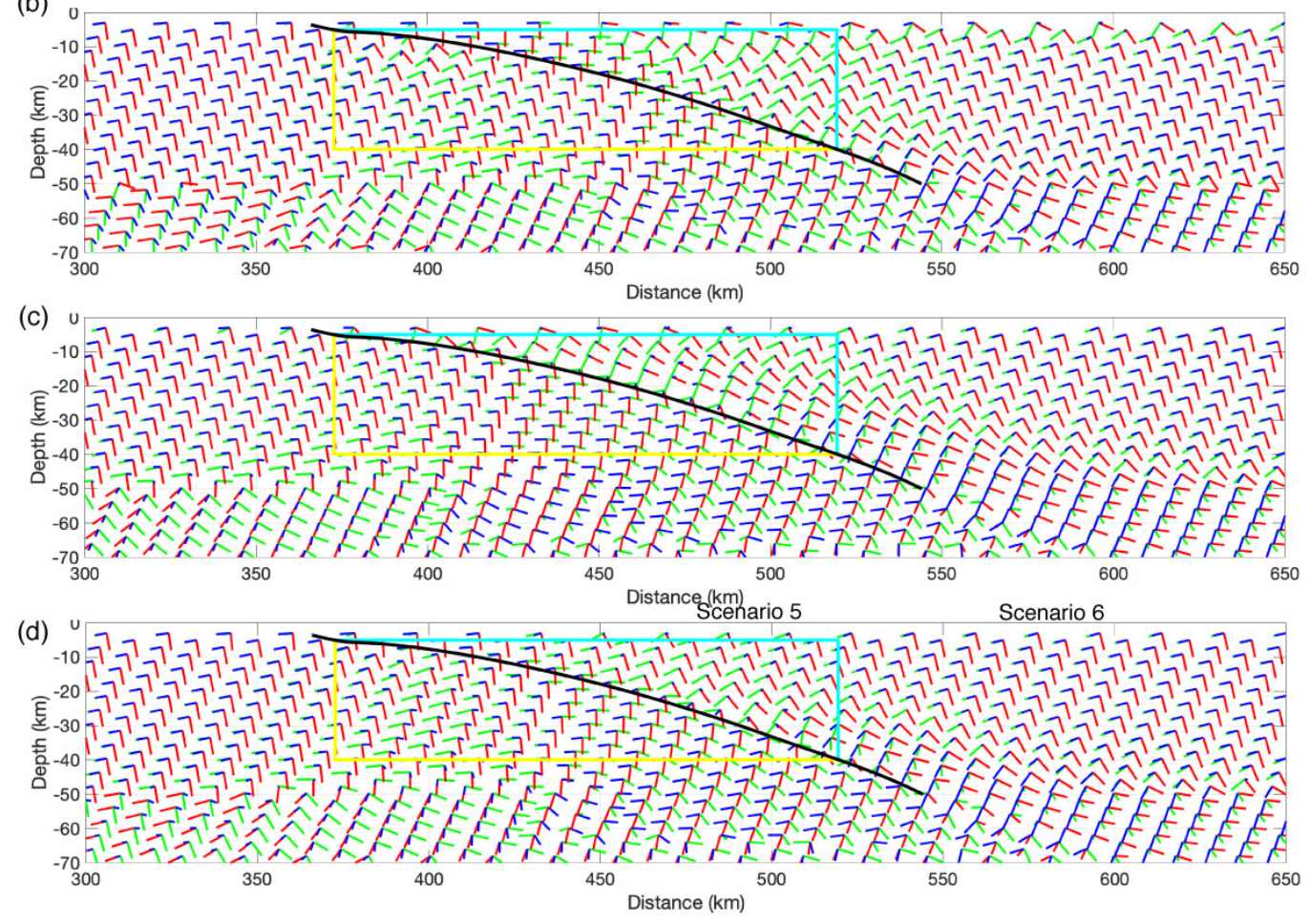

Figure A4. Orientations of the principal stresses after the earthquake in (a) Scenario 3, (b) Scenario 4, (c) Scenario 5 and (d) Scenario 6. Black line is the megathrust profile. Blue and yellow lines outline the hanging wall and footwall regions. Black box in left inset in (a) shows location of slice through the volume along the fault (yellow). 


\section{Acknowledgments}

We would like to thank Dmitry Garagash and Taras Gerya for helpful discussions, as well as the participants of the 2019 SZ4D MCS RCN Megathrust Modeling Workshop in Eugene, Oregon. Simulations were conducted using the open-source software package SeisSol, freely available at github.com/SeisSol/SeisSol. All simulation input and output files will be made accessible at the zenodo data repository. During the review process, the data is accessible here: https://bit.ly/3uuJUks. The authors acknowledge funding from the Volkswagen Foundation (project "ASCETE", grant no. 88479), the European Union's Horizon 2020 research and innovation program (TEAR ERC Starting grant no. 852992 and ChEESE Center of Excellence, grant no. 823844), the German Research Foundation (DFG) (projects GA 2465/2-1, GA 2465/3-1), by KAUST-CRG (FRAGEN, grant no. ORS-2017-CRG6 3389.02), by KONWIHR - the Bavarian Competence Network for Technical and Scientific High Performance Computing (project NewWave), and by BayLat - the Bavarian University Centre for Latin America. Computing resources were provided by the Institute of Geophysics of LMU Munich (Oeser et al., 2006) and the Leibniz Supercomputing Centre (LRZ, projects no. pr63qo and pr45fi).

\section{References}

Allmann, B. P., \& Shearer, P. M. (2009, jan). Global variations of stress drop for moderate to large earthquakes. Journal of Geophysical Research: Solid Earth, 114(1). doi: 10.1029/2008JB005821

Ammon, C. J., Ji, C., Thio, H.-K., Robinson, D., Ni, S., Hjorleifsdottir, V., ...

Wald, D. (2005, may). Rupture Process of the 2004 Sumatra-Andaman Earthquake. Science, 308(5725), 1133-1139. Retrieved from http:// www.sciencemag.org/cgi/doi/10.1126/science.1112260http://www .sciencemag.org/content/308/5725/1133 doi: 10.1126/science.1112260

Andrews, D. J. (1976). Rupture propagation with finite stress in antiplane strain. Journal of Geophysical Research (1896-1977), 81(20), 3575-3582. Retrieved from https://agupubs.onlinelibrary.wiley.com/doi/abs/10.1029/ JB081i020p03575 doi: 10.1029/JB081i020p03575

Aochi, H., \& Madariaga, R. (2003, jun). The 1999 Izmit, Turkey, earthquake: Nonplanar fault structure, dynamic rupture process, and strong ground motion. Bulletin of the Seismological Society of America, 93(3), 1249-1266. doi: 
Audet, P., Bostock, M. G., Christensen, N. I., \& Peacock, S. M. (2009). Seismic evidence for overpressured subducted oceanic crust and megathrust fault sealing. Nature, 457(7225), 76-78. doi: 10.1038/nature07650

Bao, H., Ampuero, J.-P., Meng, L., Fielding, E. J., Liang, C., Milliner, C. W., ... Huang, H. (2019). Early and persistent supershear rupture of the 2018 magnitude 7.5 palu earthquake. Nature Geoscience, 12(3), 200-205.

Bilek, S. L., \& Lay, T. $\quad$ (2018, aug). Subduction zone megathrust earthquakes. Geosphere, 14(4), 1468-1500. Retrieved from https://doi.org/10.1130/ GES01608.1 doi: 10.1130/GES01608.1

Bletery, Q., Thomas, A. M., Rempel, A. W., Karlstrom, L., Sladen, A., \& De Barros, L. (2016, nov). Mega-earthquakes rupture flat megathrusts. Science, 354(6315), 1027-1031. Retrieved from https://arxiv.org/abs/1605.09422 doi: 10.1126/science.aag0482

Breuer, A., Heinecke, A., Rettenberger, S., Bader, M., Gabriel, A. A., \& Pelties, C. (2014). Sustained petascale performance of seismic simulations with SeisSol on SuperMUC. $\quad$ In Kunkel J.M., Ludwig T., \& Meuer H.W. (Eds.), Lecture notes in computer science (including subseries lecture notes in artificial intelligence and lecture notes in bioinformatics) (Vol. 8488 LNCS, pp. 1-18). Springer, Cham. Retrieved from http://link.springer.com/10.1007/ 978-3-319-07518-1\{\_\}1 doi: 10.1007/978-3-319-07518-1_1

Brodsky, E. E., Mori, J. J., Anderson, L., Chester, F. M., Conin, M., Dunham, E. M., ... Yang, T. (2020). The State of Stress on the Fault Before, During, and After a Major Earthquake. Annual Review of Earth and Planetary Sciences, 48(1), 1-26. doi: 10.1146/annurev-earth-053018-060507

Brodsky, E. E., Saffer, D., Fulton, P., Chester, F., Conin, M., Huffman, K., ... Wu, H.-Y. (2017, aug). The postearthquake stress state on the Tohoku megathrust as constrained by reanalysis of the JFAST breakout data. Geophysical Research Letters, 44(16), 8294-8302. Retrieved from http://doi.wiley.com/ 10.1002/2017GL074027 doi: 10.1002/2017GL074027

Bürgmann, R. (2018, aug). The geophysics, geology and mechanics of slow fault slip. Earth and Planetary Science Letters, 495, 112-134. doi: 10.1016/j.epsl.2018.04 .062 
Choy, G. L., \& Boatwright, J. L. (1995). Global patterns of radiated seismic energy and apparent stress. Journal of Geophysical Research: Solid Earth, 100(B9), 18205-18228. Retrieved from https://agupubs.onlinelibrary.wiley.com/ doi/abs/10.1029/95JB01969 doi: https://doi.org/10.1029/95JB01969

De La Puente, J., Ampuero, J. P., \& Käser, M. (2009). Dynamic rupture modeling on unstructured meshes using a discontinuous Galerkin method. Journal of Geophysical Research: Solid Earth, 114(10). doi: 10.1029/2008JB006271

Di Toro, G., Han, R., Hirose, T., De Paola, N., Nielsen, S., Mizoguchi, K., ... Shimamoto, T. (2011, mar). Fault lubrication during earthquakes. Nature, 471(7339), 494-499. Retrieved from http://www.nature.com/articles/ nature09838 doi: 10.1038/nature09838

Dumbser, M., \& Käser, M. ～(2006, oct). An arbitrary high-order discontinuous Galerkin method for elastic waves on unstructured meshes - II. The three-dimensional isotropic case. Geophysical Journal International, 167(1), 319-336. Retrieved from https://academic.oup.com/ gji/article-lookup/doi/10.1111/j.1365-246X.2006.03120.x doi: 10.1111/j.1365-246X.2006.03120.x

Dunham, E. M., Belanger, D., Cong, L., \& Kozdon, J. E. (2011, oct). Earthquake ruptures with strongly rate-weakening friction and off-fault plasticity, part 2: Nonplanar faults. Bulletin of the Seismological Society of America, 101(5), 2308-2322. doi: $10.1785 / 0120100076$

Eberhart-Phillips, D., Han, D. H., \& Zoback, M. D. （1989, feb). Empirical relationships among seismic velocity, effective pressure, porosity, and clay content in sandstone. Geophysics, 54(1), 82-89. Retrieved from https:// library.seg.org/doi/abs/10.1190/1.1442580 doi: 10.1190/1.1442580

Ekström, G., Nettles, M., \& Dziewoński, A. M. (2012, jun). The global CMT project 2004-2010: Centroid-moment tensors for 13,017 earthquakes. Physics of the Earth and Planetary Interiors, 200-201, 1-9. doi: 10.1016/j.pepi.2012.04.002

Faulkner, D. R., Mitchell, T. M., Healy, D., \& Heap, M. J. $\quad$ (2006, dec). $\quad$ Slip on 'weak' faults by the rotation of regional stress in the fracture damage zone. Nature, 444(7121), 922-925. Retrieved from https://www.nature.com/ articles/nature05353 doi: 10.1038/nature05353

Fulton, P. M., Brodsky, E. E., Kano, Y., Mori, J., Chester, F., Ishikawa, T., ... 
Toczko, S. (2013). Low coseismic friction on the Tohoku-Oki fault determined from temperature measurements. Science, 342(6163), 1214-1217. doi: 10.1126/science.1243641

Gabriel, A.-A., Ampuero, J.-P., Dalguer, L. A., \& Mai, P. M.

(2013, August). Source properties of dynamic rupture pulses with off-fault plasticity. Journal of Geophysical Research: Solid Earth, 118(8), 4117-4126. doi: $10.1002 /$ jgrb.50213

Gabriel, A.-A., Vyas, J. C., Ulrich, T., Ampuero, J., \& Mai, P. M. (2020). 3D dynamic rupture modeling with thermal pressurization. In Poster \#158 at 2020 scec annual meeting (p. 08).

Gao, X., \& Wang, K. (2014). Strength of stick-slip and creeping subduction megathrusts from heat flow observations. Science, 345(6200), 1038-1041. doi: 10 $.1126 /$ science. 1255487

Garagash, D. I. (2012, apr). Seismic and aseismic slip pulses driven by thermal pressurization of pore fluid. Journal of Geophysical Research: Solid Earth, 117(4), n/a-n/a. Retrieved from http://doi.wiley.com/10.1029/2011JB008889 doi: 10.1029/2011JB008889

Hardebeck, J. L. (2012, nov). Coseismic and postseismic stress rotations due to great subduction zone earthquakes. Geophysical Research Letters, 39(21), n/an/a. Retrieved from http://doi.wiley.com/10.1029/2012GL053438 doi: 10 $.1029 / 2012$ GL053438

Harris, R. A., Barall, M., Aagaard, B., Ma, S., Roten, D., Olsen, K., ... Dalguer, L. (2018, may). A Suite of Exercises for Verifying Dynamic Earthquake Rupture Codes. $\quad$ Seismological Research Letters, 89(3), 1146-1162. Retrieved from http://scecdata.usc.edu/cvws/download/HarrisetalSRL2018 .pdfhttps://pubs.geoscienceworld.org/ssa/srl/article/89/3/ 1146/530061/A-Suite-of-Exercises-for-Verifying-Dynamic doi: $10.1785 / 0220170222$

Hayes, G. P., Wald, D. J., \& Johnson, R. L. $\quad$ (2012, jan). Slab1.0: A threedimensional model of global subduction zone geometries. Journal of Geophysical Research, 117(B1), B01302. Retrieved from http://doi.wiley.com/ 10.1029/2011JB008524 doi: 10.1029/2011JB008524

Heise, W., Caldwell, T. G., Bannister, S., Bertrand, E. A., Ogawa, Y., Bennie, S. L., 
\& Ichihara, H. (2017). Mapping subduction interface coupling using magnetotellurics: Hikurangi margin, New Zealand. Geophysical Research Letters, 44(18), 9261-9266. doi: 10.1002/2017GL074641

Heise, W., Caldwell, T. G., Bertrand, E. A., Hill, G. J., Bennie, S. L., \& Ogawa, Y. (2013, oct). Changes in electrical resistivity track changes in tectonic plate coupling. $\quad$ Geophysical Research Letters, 40(19), 5029-5033. Retrieved from https://onlinelibrary.wiley.com/doi/abs/10.1002/grl.50959 doi: $10.1002 /$ grl.50959

Hirth, G., \& Beeler, N. M. (2015). The role of fluid pressure on frictional behavior at the base of the seismogenic zone. Geology, 43(3), 223-226. doi: 10.1130/ G36361.1

Huang, Y., Ampuero, J.-P., \& Helmberger, D. V. ～(2014). Earthquake ruptures modulated by waves in damaged fault zones. Journal of Geophysical Research: Solid Earth, 119(4), 3133-3154. Retrieved from https:// agupubs.onlinelibrary.wiley.com/doi/abs/10.1002/2013JB010724 doi: https://doi.org/10.1002/2013JB010724

Hubbert, M. K., \& Rubey, W. W. $\quad$ (1959, feb). ROLE OF FLUID PRESSURE IN MECHANICS OF OVERTHRUST FAULTING I. MECHANICS OF FLUID-FILLED POROUS SOLIDS AND ITS APPLICATION TO OVERTHRUST FAULTING. GSA Bulletin, 70(2), 115-166. doi: 10.1130/0016-7606(1959)70[115:ROFPIM]2.0.CO;2

Hüpers, A., Torres, M. E., Owari, S., McNeill, L. C., Dugan, B., Henstock, T. J., ... Zhao, X. (2017, may). Release of mineral-bound water prior to subduction tied to shallow seismogenic slip off Sumatra. Science, 356(6340), 841-844. Retrieved from https://science.sciencemag.org/content/356/6340/ 841https://science.sciencemag.org/content/356/6340/841.abstract doi: $10.1126 /$ science.aal3429

Husen, S., \& Kissling, E. (2002). Postseismic fluid flow after the large subduction earthquake of Antofagasta, Chile. Geology, 29(9), 847-850. doi: 10.1130/0091 -7613(2001)029<0847:PFFATL $\rangle 2.0 . \mathrm{CO} ; 2$

Kaneko, Y., Lapusta, N., \& Ampuero, J.-P. $\quad$ (2008). Spectral element modeling of spontaneous earthquake rupture on rate and state faults: Effect of velocity-strengthening friction at shallow depths. Journal of Geo- 
physical Research: Solid Earth, 113(B9).

Retrieved from https:// agupubs.onlinelibrary.wiley.com/doi/abs/10.1029/2007JB005553 doi: https://doi.org/10.1029/2007JB005553

Karagianni, I., Papazachos, C. B., Scordilis, E. M., \& Karakaisis, G. F. Reviewing the active stress field in Central Asia by using a modified stress tensor approach. Journal of Seismology, 19(2), 541-565. doi: 10.1007/ s10950-015-9481-4

Kozdon, J. E., \& Dunham, E. M. (2013, may). Rupture to the Trench: Dynamic rupture simulations of the 11 march 2011 Tohoku earthquake. Bulletin of the Seismological Society of America, 103(2 B), 1275-1289. doi: $10.1785 / 0120120136$

Lamb, S. (2006). Shear stresses on megathrusts: Implications for mountain building behind subduction zones. Journal of Geophysical Research, 111(B7). doi: 10 $.1029 / 2005 j \mathrm{~b} 003916$

Laske, G., Masters, G., Ma, Z., \& Pasyanos, M. (2013). Update on CRUST1.0-A 1-degree global model of Earth's crust. In Egu general assembly 2013 (Vol. 15, p. 2658). Retrieved from https://ui.adsabs.harvard.edu/abs/2013EGUGA . .15.2658L/abstracthttp://meetingorganizer. copernicus.org/EGU2013/ EGU2013-2658.pdf

Madden, E. H., Bader, M., Behrens, J., Van Dinther, Y., Gabriel, A. A., Rannabauer, L., .. V Van Zelst, I. ～(2021, nov). Linked 3-D modelling of megathrust earthquake-tsunami events: From subduction to tsunami run up. Geophysical Journal International, 224(1), 487-516. Retrieved from https://academic.oup.com/gji/article/224/1/487/5920616 doi: $10.1093 /$ gji $/$ ggaa484

Madden, E. H., Maerten, F., \& Pollard, D. D. (2013). Mechanics of nonplanar faults at extensional steps with application to the 1992 M 7.3 Landers, California, earthquake. Journal of Geophysical Research: Solid Earth, 118(6), 3249-3263. doi: $10.1002 /$ jgrb.50237

Noda, H., Dunham, E. M., \& Rice, J. R. (2009, jul). Earthquake ruptures with thermal weakening and the operation of major faults at low overall stress levels. Journal of Geophysical Research: Solid Earth, 114(7), B07302. Retrieved from http://doi.wiley.com/10.1029/2008JB006143 
10.1029/2008JB006143

Oeser, J., Bunge, H. P., \& Mohr, M. (2006). Cluster design in the earth sciences tethys. In Lecture notes in computer science (including subseries lecture notes in artificial intelligence and lecture notes in bioinformatics) (Vol. 4208 LNCS, pp. 31-40). Springer Verlag. Retrieved from https://link.springer.com/ chapter/10.1007/11847366\{\_\}4 doi: 10.1007/11847366_4

Pelties, C., Gabriel, A. A., \& Ampuero, J. P. (2014). Verification of an ADER-DG method for complex dynamic rupture problems. Geoscientific Model Development, 7(3), 847-866. doi: 10.5194/gmd-7-847-2014

Petrini, C., Gerya, T., Yarushina, V., van Dinther, Y., Connolly, J., \& Madonna, C. (2020, sep). Seismo-hydro-mechanical modelling of the seismic cycle: Methodology and implications for subduction zone seismicity. Tectonophysics, 791, 228504. doi: $10.1016 /$ j.tecto.2020.228504

Ramos, M. D., Huang, Y., Ulrich, T., Li, D., Gabriel, A.-A., \& Thomas, A. (2021). Assessing margin-wide rupture behaviors along the cascadia megathrust with 3-d dynamic rupture simulations. Retrieved from https://eartharxiv.org/ repository/view/2141 doi: 10.31223/X5SC8C

Rice, J. R. (1992). Fault stress states, pore pressure distributions and the weakening of the San Andreas fault, in Fault Mechanics and the Transport Properties of Rocks : A Festschrift in Honor of $\mathrm{W}$.... $\quad$ Fault Mechanics and Transport Properties of Rocks(January 1992).

Saffer, D. M., \& Tobin, H. J. $\quad$ (2011, may). Hydrogeology and mechanics of subduction zone forearcs: Fluid flow and pore pressure.

Annual Review of Earth and Planetary Sciences, 39(1), 157-186.

Retrieved from http:// www . annualreviews .org/doi/10.1146/annurev-earth-040610-133408 doi: 10.1146/annurev-earth-040610-133408

Segall, P., \& Rice, J. R. (1995). Dilatancy, compaction, and slip instability of a fluid-infiltrated fault. Journal of Geophysical Research, 100(B11), 2215522171. doi: 10.1029/95jb02403

Seno, T. (2017, jan). Subducted sediment thickness and Mw 9 earthquakes. Journal of Geophysical Research: Solid Earth, 122(1), 470-491. Retrieved from https://onlinelibrary.wiley.com/doi/abs/10.1002/2016JB013048 doi: 10.1002/2016JB013048 
Shearer, P., \& Bürgmann, R. (2010). Lessons learned from the 2004 sumatraandaman megathrust rupture. Annual Review of Earth and Planetary Sciences, 38, 103-131. doi: 10.1146/annurev-earth-040809-152537

Sibson, R. H. (1992, sep). Implications of fault-valve behaviour for rupture nucleation and recurrence. Tectonophysics, 211(1-4), 283-293. doi: 10.1016/0040 $-1951(92) 90065-\mathrm{E}$

Strasser, F. O., Arango, M., \& Bommer, J. J. (2010). Scaling of the source dimensions of interface and intraslab subduction-zone earthquakes with moment magnitude. Seismological Research Letters, 81(6), 941-950.

Suppe, J. (2014). Fluid overpressures and strength of the sedimentary upper crust. Journal of Structural Geology, 69(PB), 481-492. Retrieved from http://ac.els-cdn.com/S0191814114001552/1-s2.0-S0191814114001552 -main.pdf?\{\_\}tid=ab34e2a6-2fd3-11e7-8700-00000aab0f6b $\{\backslash \&\}$ acdnat $=$ 1493797361\{\_\}969e5507e8ab729ea51622f0ced397e6 doi: 10.1016/ j.jsg.2014.07.009

Townend, J., \& Zoback, M. D. (2004). Regional tectonic stress near the San Andreas fault in central and southern California. Geophysical Research Letters, 31(15), 1-5. doi: 10.1029/2003GL018918

Uchide, T., Shearer, P. M., \& Imanishi, K. ～(2014, sep). Stress drop variations among small earthquakes before the 2011 Tohoku-oki, Japan, earthquake and implications for the main shock. Journal of Geophysical Research: Solid Earth, 119(9), 7164-7174. Retrieved from http://doi.wiley.com/10.1002/ 2014JB010943 doi: 10.1002/2014JB010943

Ulrich, T., Gabriel, A. A., Ampuero, J. P., \& Xu, W. (2019, dec). Dynamic viability of the $2016 \mathrm{Mw} 7.8$ Kaikōura earthquake cascade on weak crustal faults. $\mathrm{Na}$ ture Communications, 10(1), 1213. Retrieved from http://www.nature.com/ articles/s41467-019-09125-w doi: 10.1038/s41467-019-09125-w

Ulrich, T., Gabriel, A.-A., \& Madden, E. H. (2020). Stress, rigidity and sediment strength control megathrust earthquake and tsunami dynamics (Tech. Rep.). Retrieved from https://osf.io/9kdhb/ doi: 10.31219/OSF.IO/9KDHB

Uphoff, C., Rettenberger, S., Bader, M., Madden, E., Ulrich, T., Wollherr, S., \& Gabriel, A.-A. (2017). Extreme scale multi-physics simulations of the tsunamigenic 2004 sumatra megathrust earthquake. In Proceedings of the international 
conference for high performance computing, networking, storage and analysis, sc 2017. doi: 10.1145/3126908.3126948

Wang, X., \& Morgan, J. K. (2019). Controls on Fore-Arc Deformation and Stress Switching After the Great 2011 Tohoku-Oki Earthquake From Discrete Numerical Simulations. Journal of Geophysical Research: Solid Earth, 124(8), 9265-9279. doi: 10.1029/2019JB017420

Weng, H., \& Ampuero, J.-P. (2019). The dynamics of elongated earthquake ruptures. Journal of Geophysical Research: Solid Earth, 124(8), 8584-8610. Retrieved from https://agupubs.onlinelibrary.wiley.com/doi/abs/ 10.1029/2019JB017684 doi: https://doi.org/10.1029/2019JB017684

Wirp, S. A., Gabriel, A.-A., Madden, E. H., Schmeller, M., van Zelst, I., Krenz, L., ... Rannabauer, L. (2021). 3D linked subduction, dynamic rupture, tsunami and inundation modeling: dynamic effects of supershear and tsunami earthquakes, hypocenter location and shallow fault slip. Frontiers in Earth Science, 9, 177. doi: 10.3389/FEART.2021.626844

Wollherr, S., Gabriel, A. A., \& Uphoff, C. $\quad$ (2018, sep). Off-fault plasticity in three-dimensional dynamic rupture simulations using a modal Discontinuous Galerkin method on unstructured meshes: Implementation, verification and application. Geophysical Journal International, 214(3), 1556-1584. Retrieved from https://academic.oup.com/gji/article/214/3/1556/5017447 doi: 10.1093/GJI/GGY213

Yao, S., \& Yang, H. (2020, jun). Rupture Dynamics of the 2012 Nicoya Mw 7.6 Earthquake: Evidence for Low Strength on the Megathrust. Geophysical Research Letters, 47(13). Retrieved from https://onlinelibrary.wiley.com/ doi/abs/10.1029/2020GL087508 doi: 10.1029/2020GL087508

Zelst, I., Wollherr, S., Gabriel, A., Madden, E. H., \& Dinther, Y. $\quad$ (2019, nov). Modeling Megathrust Earthquakes Across Scales: One-way Coupling From Geodynamics and Seismic Cycles to Dynamic Rupture. Journal of Geophysical Research: Solid Earth, 124(11), 11414-11446. Retrieved from https://onlinelibrary.wiley.com/doi/10.1029/2019JB017539 doi: 10.1029/2019JB017539

Zelst, I. v., Rannabauer, L., Gabriel, A.-A., \& Dinther, Y. v. (2020). Earthquake rupture on multiple splay faults and its effect on tsunamis. EarthArXiv, 1-20. 
Retrieved from https://eartharxiv.org/repository/view/1939/

Zhu, W., Allison, K. L., Dunham, E. M., \& Yang, Y. (2020, dec). Fault valving and pore pressure evolution in simulations of earthquake sequences and aseismic slip. Nature Communications, 11(1), 1-11. Retrieved from https://doi.org/ 10.1038/s41467-020-18598-z doi: 10.1038/s41467-020-18598-z 